Reviews in Applied Electrochemistry Number 62

\title{
Deposition of clusters and nanoparticles onto boron-doped diamond electrodes for electrocatalysis
}

\author{
G. SINÉ, I. DUO, B. EL ROUSTOM, G. FÓTI and CH. COMNINELLIS* \\ Institute of Chemical Sciences and Engineering, Ecole Polytechnique Fédérale de Lausanne (EPFL), Station 6, \\ Building $\mathrm{CH}, \mathrm{CH}-1015$, Lausanne, Switzerland \\ (*author for correspondence, tel.:+41-21-6933674,fax:+41-21-6935690,e-mail: christos.comninellis@epfl.ch)
}

Received 30 November 2005; accepted in revised form 12 May 2006

Key words: BDD electrode, Nanoparticles, Dendrimer, Electrocatalysis, Electrodeposition, Microemulsion, Thermal decomposition, Oxygen evolution, Methanol oxidation

\begin{abstract}
Metal and metal oxide particles and nanoparticles, differing from each other by their nature and synthesis technique, were deposited onto boron-doped diamond (BDD) thin film electrodes. The applicability in electrocatalysis of thermally decomposed $\mathrm{IrO}_{2}$ and $\mathrm{Au}$ nanoparticles, electrodeposited $\mathrm{Pt}$ particles, dendrimer-encapsulated $\mathrm{Pt}$ nanoparticles (Pt DENs) and microemulsion-synthesized $\mathrm{Pt} / \mathrm{Ru}$ nanoparticles was studied, once deposited on BDD substrate. In all cases, the electrochemical response of the composite electrodes could be solely attributed to the supported particles. All the particles, with the exception of Pt DENs, exhibited electrocatalytic activity. Pt DENs inactivity has been attributed to insufficient removal of the dendrimer polymer matrix. It was concluded that the BDD electrode is a suitable substrate for the electrochemical investigation of supported catalytic nanoparticles.
\end{abstract}

\section{Introduction}

The study of metallic and metal oxide nanoparticles has attracted a growing interest, due to the different properties of nanoparticles compared to those of bulk materials [1]. The study, both fundamental and applied, of nanoparticulate materials covers fields as different as physics, magnetism, optics and electronics. From an electrochemical point of view, the investigation of such nanoparticles is also of major interest. For instance, phenomena such as the so-called "size effect" [2-4] in electrocatalysis are still under debate.

However, the supports commonly used for the electrochemical characterization of nanoparticles are subject to corrosion (graphite and glassy carbon) or oxide formation (gold substrates). These phenomena can modify the intrinsic response of the supported particles (metal-support interactions), so that an inert substrate is needed. When properly doped with boron, synthetic diamond becomes conductive. Thus, synthetic borondoped diamond (BDD) thin films, deposited for instance by Chemical Vapour Deposition (CVD) on Si substrates, can be used as an electrode. The main properties of the BDD thin film electrode are the inert character of its surface, a very low background current, a large electrochemical window available between hydrogen and oxygen evolution, and an extreme resistance to chemical and electrochemical attacks [5-7]. The BDD electrode has been widely used for oxidation of organic pollutants and wastewater treatment [8-12], but its outstanding properties also make it an attractive substrate for the electrochemical characterization of supported electrocatalytic nanoparticles. The use of the BDD electrode is a possible solution to avoiding some problems encountered with other common substrates. Thus, the BDD electrode has been recently regarded as a substrate for nanoparticles such as lead [13] and titanium [14] dioxide, ruthenium [15] and iron [16] hydrous oxide. It has been shown, for instance, that the presence of thermally decomposed $\mathrm{IrO}_{2}$ nanoparticles (diameter about $10 \mathrm{~nm}$ ) on a BDD substrate strongly affects the electrochemical response of the diamond electrode, Thus, the behaviour of the composite electrode can be totally attributed to the electrochemical properties of the particles [17], even at low deposited $\mathrm{IrO}_{2}$ loadings. Such a BDD- $\mathrm{IrO}_{2}$ composite electrode can be considered like a diamond matrix, on which particles are deposited more or less homogeneously. The reaction under study (oxygen evolution or organic oxidation) takes place on diamond as well as on the deposited $\mathrm{IrO}_{2}$. Distinct reaction rates are associated with both processes, the reaction rate being higher on $\mathrm{IrO}_{2}$ nanoparticles than on diamond. In addition, metal nanoparticles have been deposited on BDD substrates. 
Gold and platinum nanoparticles have received special attention, due to their applicability for the electrocatalysis of oxygen reduction and methanol electrooxidation, respectively. BDD-Au [18-20] and BDD-Pt [21-24] composite electrodes have been prepared using different techniques, and they have exhibited high electrocatalytic activity towards oxygen reduction and methanol oxidation, respectively. It has also been shown that highly reactive hydroxyl radicals, electrogenerated on BDD from water discharge at high overpotentials [25], can both clean microemulsion-synthesized Pt nanoparticles from the residual surfactant (coming from the synthesis procedure) and participate in the methanol oxidation process [22]. Pt particles can also be entrapped into the diamond matrix, by performing an additional step of diamond layer deposition on top of the particles deposited on the substrate [26, 27]. In spite of the high resistivity and durability of this composite electrode, a significant loss in electrocatalytic activity can be expected, due to the decrease in accessible catalytic area.

Electrodeposition is one of the most widely used methods for the preparation and deposition of particles on BDD. However, thermal decomposition [18] and microemulsion synthesis [22] have also been successfully used in our laboratory to deposit metallic particles on diamond substrates. The spontaneous deposition of metal particles from solutions of metal ions or complexes have also been reported on BDD electrodes [28]. It was stated that the electrons needed for the reduction of ions come from the conductive underlying Si layer.

The contribution of our group to the field of electrochemistry of supported clusters and nanoparticles is emphasized here. Our work mainly focuses on $\mathrm{IrO}_{2}$ and $\mathrm{RuO}_{2}$ [17], $\mathrm{Au}$ [18], Pt [21, 22] and Pt-based alloy particles. The choice of these materials was motivated by their numerous and useful potential application in electrocatalysis: oxygen reduction $\left(\mathrm{IrO}_{2}, \mathrm{RuO}_{2}, \mathrm{Au}\right)$, $\mathrm{CO}$ oxidation $\mathrm{Au}$ ) $[29,30]$, and alcohol (methanol or ethanol) electrooxidation (Pt and Pt-based particles) [31-33]. A large range of synthesis methods has been explored. They have been classified into three groups: (i) thermal decomposition, (ii) electrodeposition and (iii) colloidal (microemulsion and dendrimeric) techniques. These methods are well known to be efficient ways to prepare particles and nanoparticles. However, the shape and size distribution of the obtained particles depend strongly on the synthesis technique. For instance, the microemulsion $[34,35]$ and dendrimeric $[36,37]$ methods allow the preparation of nanoparticles of diameter as low as $1-2 \mathrm{~nm}$ with narrow size distribution, whereas such achievements remain difficult with electrodeposition on BDD [24].

$\mathrm{IrO}_{2}$ and $\mathrm{Au}$ particles have been synthesized by the thermal decomposition technique, $\mathrm{Pt}$ particles were made by electrodeposition or colloidal methods (microemulsion and dendrimer), and synthesis of Pt-Ru nanoparticles was performed using the microemulsion method. These methods will be discussed in terms of average size, stability and applicability of the resulting particles in electrocatalysis. For this purpose, particles have been investigated by physical (electron microscopy, surface analysis) and electrochemical techniques. The electrocatalytic activity of particles towards reactions of technological interest (oxygen reduction, methanol and ethanol electrooxidation) has also been specifically studied.

\section{Experimental}

\subsection{BDD electrode preparation}

BDD films were prepared by the hot filament chemical vapour deposition technique (HF-CVD) on single crystal $p$-Si (100) wafers $(1-3 \mathrm{~m} \Omega \mathrm{cm}$, Siltronix). The process gas was a mixture of $1 \% \mathrm{CH}_{4}$ in $\mathrm{H}_{2}$, containing trimethylboron to allow diamond doping. The filament temperature was between $2440{ }^{\circ} \mathrm{C}$ and $2560{ }^{\circ} \mathrm{C}$ and that of the substrate was maintained at $830^{\circ} \mathrm{C}$. Film growth occurred at a rate of $0.24 \mu \mathrm{m} \mathrm{h}^{-1}$. The grain size of the BDD films lay between $200 \mathrm{~nm}$ and $800 \mathrm{~nm}$ and the film thickness was about $1 \mu \mathrm{m}$ with a resistivity in the 10 $30 \mathrm{~m} \Omega \mathrm{cm}$ range. The doping level of boron, expressed as $B / C$ ratio, was between $2500 \mathrm{ppm}$ and $3500 \mathrm{ppm}$, which corresponds to a carrier concentration ranging from $4.9 \times 10^{20}$ to $6.9 \times 10^{20}$ atom cm$~^{-3}$. The BDD substrate could be used without additional surface pretreatment (as-grown BDD: $\mathrm{BDD}_{\mathrm{ag}}$ ), or after anodic polarization $\left(10 \mathrm{~mA} \mathrm{~cm}{ }^{-2}\right.$ in $1 \mathrm{M} \mathrm{H}_{2} \mathrm{SO}_{4}$ at $25^{\circ} \mathrm{C}$ for $30 \mathrm{~min})$ to remove most of the non-diamond $\left(\mathrm{C} \mathrm{sp}^{2}\right)$ and adsorbed hydrogen impurities from the surface (mildly polarized BDD: $\mathrm{BDD}_{\text {mild }}$ ) [9]. In each case the BDD electrode surface was rinsed once with 2-propanol or acetone and twice with Milli-Q water in an ultrasonic bath before use.

\subsection{Measurements}

Electrochemical measurements were performed in a conventional three-electrode cell using a computer controlled EcoChemie potentiostat (model Autolab PGstat 30). Composite electrodes (BDD-supported particles; exposed area of BDD: 0.4 or $1 \mathrm{~cm}^{2}$ depending on the cell) were used as working electrode, $\mathrm{Hg} / \mathrm{Hg}_{2} \mathrm{SO}_{4}$. $\mathrm{K}_{2} \mathrm{SO}_{4}$ (sat.) as reference and $\mathrm{Pt}$ wire as counter electrode. All potentials are expressed with respect to the Standard Hydrogen Electrode (SHE). All solutions were made with ultra-pure water (Milli-Q) and analytical grade reagents and were saturated with nitrogen gas prior to each experiment since Pt was involved in the measurement.

Transmission Electron Microscopy (TEM) and Scanning Electron Microscopy (SEM) were used to characterize the morphology of particles. TEM experiments were carried out using a Philips CM 300 microscope to analyze Pt-based particles (made by the microemulsion and dendrimer methods) and $\mathrm{IrO}_{2}$ clusters. A small droplet of the aqueous suspension of Pt-based particles 
was deposited onto an amorphous carbon-coated copper grid, and the excess water was removed before analysis. To determine the morphology of very low loadings of $\mathrm{IrO}_{2}$ particles on BDD surfaces, crystals were cleaved along weakly bonded planes to obtain an atomically smooth surface. Wedge-shaped samples were placed on a copper support and observed by a beam parallel to the (100) direction. In this way, the profile of the BDD crystal could be observed and a very thin portion of the surface was investigated. SEM, using a JEOL JMS-6300-F scanning electron microscope at magnification up to 60000 , was used to investigate gold deposits and platinum electrodeposits on BDD.

Identification of the oxidation state of metals was carried out by X-ray Photoelectron Spectroscopy (XPS), using a Kratos Axis-Ultra spectrometer with a monochromatic $\mathrm{Al} \mathrm{K}_{\alpha} \mathrm{X}$-ray source, operated at $15 \mathrm{kV}$ and a pass energy of $20 \mathrm{eV}$. A total area of $700 \times 300 \mu \mathrm{m}$ was investigated over a thickness of 50-100 $\AA$. The peaks of interest of the signals (Pt4f doublet for example) were deconvoluted using the CasaXPS ${ }^{\circledR}$ computer software. The crystalline structure of microemulsion-synthesized samples was determined by X-ray Diffraction (XRD) using a Siemens D500 Powder Diffractometer. Measurements were performed using the $\mathrm{K}_{\alpha} \mathrm{Cu}$ ray $(1.54 \AA$ ), with slits of $1^{\circ} / 1^{\circ} / 1^{\circ} / 0.05^{\circ}$ into the $5-90^{\circ}$ range, with a step of $0.04^{\circ}$ and a resolution of $4 \mathrm{~s} / \mathrm{step}$.

\subsection{Synthesis and deposition of nanoparticles}

\subsection{1. $\mathrm{IrO}_{2}$ and $\mathrm{Au}$ particles by thermal decomposition}

$\mathrm{IrO}_{2}$ particles were deposited onto $\mathrm{BDD}_{\text {mild }}$ hydrophilic surface by thermal decomposition. Solutions of $\mathrm{H}_{2} \mathrm{IrCl}_{6}$ in 2-propanol were prepared with different precursor concentrations, in order to vary the amount of deposited $\mathrm{IrO}_{2}$. About $5 \mu \mathrm{L}$ of the precursor solution were placed on the BDD surface for a single deposition step. After solvent evaporation at $80{ }^{\circ} \mathrm{C}$, calcination was performed at $450{ }^{\circ} \mathrm{C}$ to oxidize the precursor acid to $\mathrm{IrO}_{2}$. A value of $10^{15}$ molecules $\mathrm{IrO}_{2} \mathrm{~cm}^{-2}$ was defined as the loading corresponding to $\Gamma=1$. $\mathrm{IrO}_{2}$ loadings investigated here correspond to $\Gamma$ values ranging from 0.6 to 6.4 .

Gold was deposited onto the $\mathrm{BDD}_{\mathrm{ag}}$ substrate using the sputtering technique in an inert atmosphere and at room temperature. The direct current (dc) mode with a discharge of $330 \mathrm{~V}$ and an argon pressure of $10^{-2}$ mbar were the working conditions. As determined by profilometric measurement (Alphastep, Model 500) of the film thickness (in the 5-30 nm range) on smooth silicon samples processed simultaneously, the deposition rate was $0.3 \mathrm{~nm} \mathrm{~s}^{-1}$. This result is in good agreement with the mass deposition rate of $0.51 \mu \mathrm{g} \mathrm{s}^{-1}$ per $1 \mathrm{~cm}^{2}$ geometrical surface area, determined by Atomic Absorption Spectroscopy (AAS), performed with an equipment of Shimadzu Model AA-6650, after complete dissolution of the gold deposit in aqua regia at $80^{\circ} \mathrm{C}$ for $30 \mathrm{~min}$. The equivalent uniform thickness of the sputtered gold deposits were estimated from the exposure time and the roughness of the substrate. The gold deposits on BDD prepared by short-time (6 and $12 \mathrm{~s}$ ) sputtering were then heated at high temperature $\left(600^{\circ} \mathrm{C}\right.$ in air) to yield stable gold nanoparticles.

\subsubsection{Electrodeposition of Pt particles}

Electrodeposition of Pt particles was performed using the electrochemical set-up described in Sect. 2.2. Deposition was performed on a $\mathrm{BDD}_{\text {mild }}$ working electrode from a solution of $2 \mathrm{mM} \mathrm{H}_{2} \mathrm{PtCl}_{6}$ in $1 \mathrm{M} \mathrm{HClO}_{4}$, by applying a potential step from the equilibrium potential $(1 \mathrm{~V})$ to a potential at which platinic ions are reduced $(0.02-0.1 \mathrm{~V})$. The solution was saturated with nitrogen gas before deposition and the deposition process and mechanism were studied by chronoamperometry.

\subsubsection{Colloidal syntheses of Pt and Pt-based binary nanoparticles}

Synthesis of Pt particles via the dendrimeric route was performed according to a published procedure [38]. A polyamidoamine (PAMAM) amine-terminated dendrimer of 4 th generation $\left(\mathrm{G}_{4}-\mathrm{NH}_{2}\right)$, diluted at $10 \mathrm{wt} \%$ in methyl alcohol (Aldrich), was used as the dendrimer source. The solvent was removed and the quantity of dendrimer necessary to yield a $2.5-50 \mu \mathrm{M}$ solution was diluted in ultra-pure water (Milli-Q). The $\mathrm{pH}$ of the solution was adjusted to 5 by addition of $\mathrm{HCl}$ in order to favour complexion of $\mathrm{Pt}^{2+}$ ions with internal $\mathrm{NH}_{2}$ groups rather than with external $\mathrm{NH}_{2}$ terminations. $\mathrm{A}$ solution of $0.1 \mathrm{M} \mathrm{H}_{2} \mathrm{PtCl}_{6}$ in ultra-pure water was added to the dendrimeric solution to yield a $\mathrm{Pt}^{2+} / \mathrm{G}_{4}-\mathrm{NH}_{2}$ molar ratio ranging from 30 to 60 . This mixture was then continuously stirred for 4 days. Finally, $0.1-0.5 \mathrm{M}$ $\mathrm{NaBH}_{4}$ solution (Aldrich) in ultra-pure water was added (quantity necessary for the reducing agent to be twenty times in excess), to reduce the complex ion. The $\mathrm{pH}$ of the solution was then adjusted to 8 . This procedure leads to the formation of dendrimer-encapsulated Pt nanoparticles (Pt DENs).

Microemulsion-synthesized platinum and platinumbased nanoparticles were obtained by reduction of $\mathrm{H}_{2} \mathrm{PtCl}_{6}$ or mixtures of $\mathrm{H}_{2} \mathrm{PtCl}_{6}$ with a second metallic salt with solid sodium borohydride in a water-in-oil (w/o) microemulsion of water/tetraethyleneglycolmonododecylether $\left(\mathrm{BRIJ}^{\circledR}-30\right) / n$-heptane. $\mathrm{RuCl}_{3}$ was used as second metallic precursor for the preparation of $\mathrm{Pt} / \mathrm{Ru}$ particles. The microemulsions were prepared using ultra-pure water (Milli-Q). BRIJ ${ }^{\circledR}-30$ and $n$-heptane were purchased from Fluka and Riedel-de-Haën, respectively, and were used as received. The aqueous phase was composed of appropriate ratios of $0.1 \mathrm{M}$ aqueous solutions of the metallic precursors (Fluka, analytical grade). The water-to-surfactant molar ratio $\left(\omega_{0}\right)$ of this w/o microemulsion was adjusted to a value of 3.8 and the quantity of surfactant represented $16.54 \%$ of the total volume. The synthesis was realised by adding to this microemulsion the quantity of solid sodium borohydride (Aldrich) necessary to yield a reducing agent concentration of $1 \mathrm{M}$ in the aqueous phase. After complete reduction in a few minutes, acetone was 
added to the solution to cause phase separation and precipitation of the particles. The precipitate was rinsed several times with acetone and ultra-pure water and then centrifuged for a few minutes to eliminate most of the surfactant. Finally, particles were put in a small volume of ultra-pure water as a suspension. The quantity of $\mathrm{Pt}$ in the suspension was determined by AAS. The deposition of such synthesized particles was performed by placing a small droplet $(5 \mu \mathrm{L})$ of an aqueous suspension of particles onto the $\mathrm{BDD}_{\text {mild }}$ substrate. The excess water was then removed under nitrogen atmosphere.

\section{Results and discussion}

\subsection{Thermally decomposed $\mathrm{IrO}_{2}$}

The morphological characterization of $\mathrm{BDD}-\mathrm{IrO}_{2}$ electrodes with different $\mathrm{IrO}_{2}$ loading $(\Gamma)$ was realized by TEM (data not shown). At low $\mathrm{IrO}_{2}$ loading, isolated $\mathrm{IrO}_{2}$ particles had a size of about $2-3 \mathrm{~nm}$ and were concentrated at the grain boundaries of the diamond crystals. At higher $\mathrm{IrO}_{2}$ loading, the particles were larger $(10 \mathrm{~nm})$ and their concentration at the grain boundaries of the diamond crystals was significantly higher. However, the most informative in situ characterization of oxide electrodes can be performed by cyclic voltammetry $(\mathrm{CV})$ in solutions of inert electrolyte over a range of potentials where the solvent is not electrochemically decomposed. It is known that surface changes occur only on the active surface sites of thermally prepared oxides [39-41].

In the case of DSA-type $\mathrm{IrO}_{2}$ electrodes with $\mathrm{Ti}$ as substrate, good $\mathrm{CV}$ spectra of the surface transitions could not be obtained due to "segregation" phenomena of $\mathrm{TiO}_{x}$ at the electrode surface [42]. Because of the inert nature of the $\mathrm{BDD}$ material, this problem was not arisen with $\mathrm{BDD}-\mathrm{IrO}_{2}$ electrodes. The voltammetric curves obtained with $\mathrm{BDD}-\mathrm{IrO}_{2}$ electrodes provided a fingerprint of electrode surface transitions occurring during the potential scan. Figure 1A shows the response of a BDD- $-\mathrm{IrO}_{2}(\Gamma=6.4)$ electrode, recorded by cyclic voltammetry at $2 \mathrm{~V} \mathrm{~s}^{-1}$ (curve 2), in comparison with the background current of a bare BDD electrode (curve 1). The high capacitive current is related to changes in the oxidation state of the $\mathrm{IrO}_{2}$ surface during the potential scan. The two pairs of peak, seen at 0.4 and $0.95 \mathrm{~V}$, can be related to the surface redox couples $\operatorname{Ir}(\mathrm{III}) / \operatorname{Ir}(\mathrm{II})$ and $\operatorname{Ir}(\mathrm{IV}) / \operatorname{Ir}(\mathrm{III})$, respectively [43, 44]. The broadness of the peaks is due probably to different degrees of hydration of the oxide lattice [45]. The very low currents recorded at a BDD electrode are certainly related to the absence of electroactive surface functionalities on the electrode surfaces. The capacitance was also calculated from the total anodic and cathodic currents, $i$, as a function of the scan rate, $v$, for each $\mathrm{IrO}_{2}$ loading (Eq. 1).

$$
i=2 C v
$$
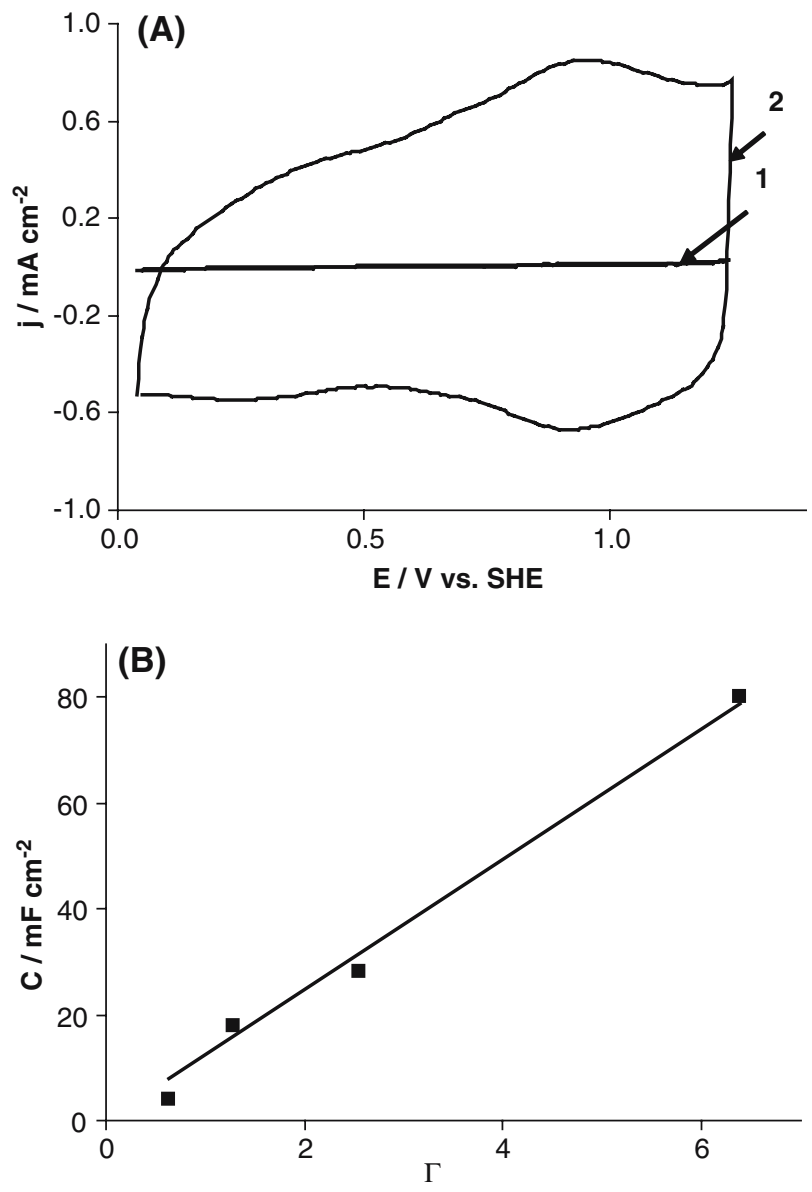

Fig. 1. (A): Cyclic voltammograms: (1) $\mathrm{BDD}_{\text {mild }}$ electrode, (2) BDD- $-\mathrm{IrO}_{2}$ electrode with $\Gamma=6.4$ prepared at $450{ }^{\circ} \mathrm{C}$. Electrolyte: $0.5 \mathrm{M} \mathrm{H}_{2} \mathrm{SO}_{4}$; scan rate $2000 \mathrm{mV} \mathrm{s} \mathrm{s}^{-1} . T=25^{\circ} \mathrm{C}$. $\Gamma=1$ corresponds to $10^{15}$ molecules $\mathrm{IrO}_{2} \mathrm{~cm}^{-2}$. (B): Capacitance values $\left(E=0.64\right.$, scan rate $\left.20 \mathrm{mV} \mathrm{s}^{-1}\right)$ as a function of $\mathrm{IrO}_{2}$ loading on BDD electrodes.

The values obtained are shown in Fig. 1B, which indicates a considerable increase in capacitance with increasing $\mathrm{IrO}_{2}$ loading due to the high activity of the $\mathrm{IrO}_{2}$ surface sites. A pseudocapacitance could in fact be defined for $\mathrm{BDD}-\mathrm{IrO}_{2}$ electrodes, which includes the double-layer capacitance (typical value for a $\mathrm{BDD}_{\text {mild }}$ electrode is $16 \mu \mathrm{F} \mathrm{cm}^{-2}$ ) and a capacitance due to the redox transitions of surface redox couples. The influence of $\mathrm{IrO}_{2}$ on the properties of diamond was tested in the presence of the outer-sphere redox couple of ferri/ ferrocyanide as redox probe. Cyclic voltammetry was performed for all $\mathrm{IrO}_{2}$ loadings in order to investigate the reversibility as a function of catalyst loading (Fig. 2). At bare diamond electrode (Fig. 2A), the outer-sphere redox system exhibited irreversible behaviour. However, the reversibility increased with increasing $\mathrm{IrO}_{2}$ loading (Fig. 2B, C). Increasing height of the current peaks is indicative of the extremely high electrocatalytic activity of the $\mathrm{IrO}_{2}$ nanoparticles, even at very low loadings (Fig. 2B). The kinetic parameters were calculated from the dependence of the voltammetric response on the scan rate. The potential difference between the anodic and the cathodic peak, $\Delta E$, and the 

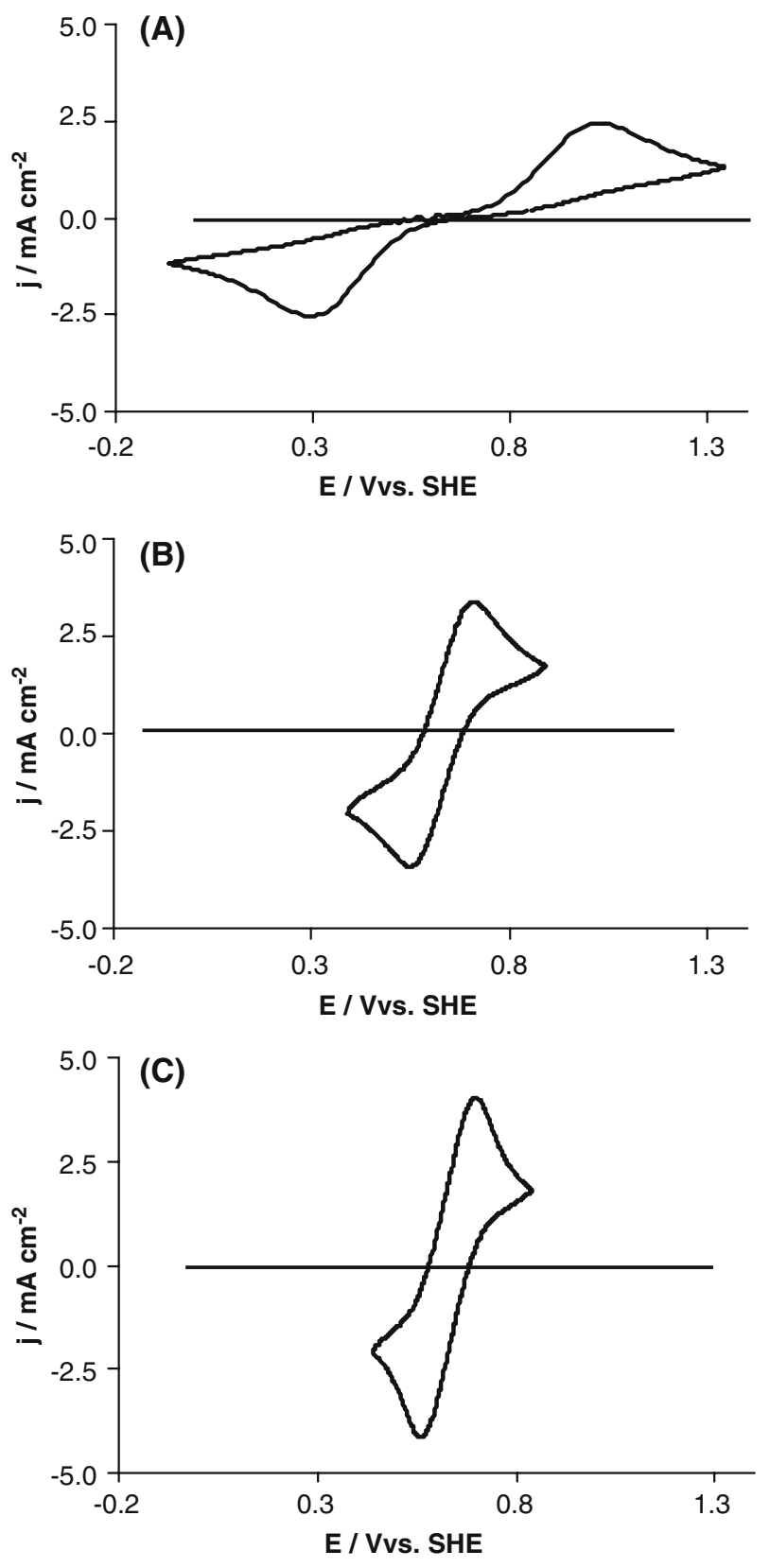

Fig. 2. Cyclic voltammograms recorded in $0.5 \mathrm{M} \mathrm{H}_{2} \mathrm{SO}_{4}$ containing $\mathrm{Fe}(\mathrm{CN})_{6} \mathrm{III} / \mathrm{II} 12.5 \times 10^{-3} / 12.5 \times 10^{-3} \mathrm{M}$ at a $\mathrm{BDD}_{\text {mild }}$ electrode (A), a BDD- $\mathrm{IrO}_{2}$ electrode with $\Gamma=0.6$ (B) and a $\mathrm{BDD}-\mathrm{IrO}_{2}$ electrode with $\Gamma=6.4(\mathrm{C})$. Scan rate: $100 \mathrm{mV} \mathrm{s}{ }^{-1}$. Geometric surface area: $1 \mathrm{~cm}^{2} . \Gamma=1$ corresponds to $10^{15}$ molecules $\mathrm{IrO}_{2} \mathrm{~cm}^{-2}$.

transfer coefficients, $\alpha_{\text {red }}$ and $\beta_{\text {ox }}$, as well as the reaction rate constants, $k^{0}$, were determined using Eq. 2 . The results are shown in Table 1.

$$
\begin{aligned}
& E_{\mathrm{p}} \\
& =E^{0}+\frac{R T}{\alpha n F}\left(0.78-\ln k^{0}+\ln \sqrt{D^{0} \frac{\alpha n F}{R T}}\right)-\frac{R T}{2 \alpha F} \ln v
\end{aligned}
$$

The sum of the transfer coefficients, $\alpha$ and $\beta$, was lower than unity for diamond electrodes but increased after $\mathrm{IrO}_{2}$ deposition. Values of $\alpha+\beta<1$ indicate that the electron transfer process was hindered on the diamond surface $\left(\mathrm{BDD}_{\text {mild }}\right)$, while $\mathrm{IrO}_{2}$ promoted the charge transfer through the electrode/electrolyte interface. A resistance to charge transfer at the electrode/electrolyte interface seemed to be the cause of the irreversibility of redox reactions on diamond. The fact that $\mathrm{IrO}_{2}$ deposition improved the reaction kinetics demonstrates that this resistance was not related to the resistivity of the diamond film but to the lack of active surface sites at the electrode/electrolyte interface.

DSA-type $\mathrm{IrO}_{2}$ electrodes (DSA-O $\mathrm{O}_{2}$ ) are widely employed as anodes in galvanic processes and electrowinning because of their high electrochemical stability under anodic oxygen evolution conditions [46]. Diamond electrodes exhibit very high stability under the same conditions, but this electrode is not a suitable material for such applications due to the high overvoltage for this reaction. The effect of $\mathrm{IrO}_{2}$ particles deposited on diamond on the oxygen evolution reaction was also investigated. Cyclic voltammetry was performed in $0.5 \mathrm{M} \mathrm{H}_{2} \mathrm{SO}_{4}$ in the potential region of electrolyte decomposition in order to study the oxygen evolution reaction (OER), an inner-sphere reaction, at $\mathrm{BDD}$ and $\mathrm{BDD}-\mathrm{IrO}_{2}$ electrodes. A potential shift of almost $1 \mathrm{~V}$ was noticed between BDD and BDD- $\mathrm{IrO}_{2}$ electrodes (Fig. 3). At bare diamond, the process took place at very high overpotentials while at $\mathrm{BDD}-\mathrm{IrO}_{2}$, oxygen evolution took place at $1.45 \mathrm{~V}$, close to the equilibrium potential of the redox system $\operatorname{Ir}(\mathrm{VI}) / \operatorname{Ir}(\mathrm{IV})$ $(1.35 \mathrm{~V})$. The current increased sharply at the OER potential, indicating a high electrocatalytic activity of BDD- $-\mathrm{IrO}_{2}$ electrodes. The behaviour of the BDD- $\mathrm{IrO}_{2}$ electrodes can be interpreted entirely as that of $\mathrm{IrO}_{2}$ continuous-film electrodes. Diamond merely acts as an inert substrate on which the catalytic activity of deposited $\mathrm{IrO}_{2}$ particles can be investigated without interference. In terms of data normalized to the $\mathrm{IrO}_{2}$ loading (results not shown), all electrodes exhibited similar electrocatalytic properties. Surface-modified diamond electrodes can be considered as a diamond matrix in which particles are deposited more or less homogeneously. The reaction takes place on diamond as well as on the active sites ( $\mathrm{IrO}_{2}$ particles). However, the reaction is much faster on the deposited $\mathrm{IrO}_{2}$ nanoparticles than on diamond.

Because of its high chemical and electrochemical stability, BDD has been investigated as an electrode for the oxidation of organic substances (inner-sphere reactions). A wide range of organic compounds have already been tested [8-12], and the powerful electrochemical properties of diamond were confirmed. While

Table 1. Parameters of the redox system $\mathrm{Fe}(\mathrm{CN})_{6}$ III/II $12.5 \times 10^{-3}$ / $12.5 \times 10^{-3} \mathrm{M}$ in $0.5 \mathrm{M} \mathrm{H}_{2} \mathrm{SO}_{4}$ at BDD electrodes with different $\mathrm{IrO}_{2}$ loadings, $\Gamma$

\begin{tabular}{lllll}
\hline Electrodes & $\Delta E / \mathrm{V}$ & $\beta_{\text {ox }}$ & $\alpha_{\text {red }}$ & $k^{0} / \mathrm{cm} \mathrm{s}^{-1}$ \\
\hline $\mathrm{BDD}_{\text {mild }}$ & 0.53 & 0.3 & 0.3 & $8 \times 10^{-5}$ \\
$\mathrm{BDD}-\mathrm{IrO}_{2}(\Gamma=0.6)$ & 0.10 & 0.5 & 0.5 & $2 \times 10^{-3}$ \\
${\mathrm{BDD}-\mathrm{IrO}_{2}(\Gamma=6.4)}$ & 0.09 & 0.5 & 0.5 & $3 \times 10^{-3}$ \\
\hline
\end{tabular}




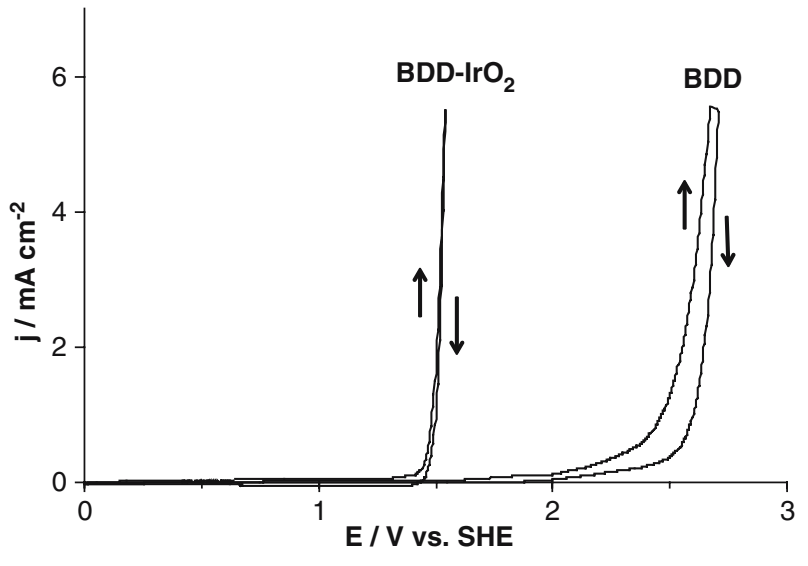

Fig. 3. Cyclic voltammograms recorded at $\mathrm{BDD}$ and $\mathrm{BDD}-\mathrm{IrO}_{2}$ ( $\Gamma=6.4$ ) electrodes in $0.5 \mathrm{M} \mathrm{H}_{2} \mathrm{SO}_{4}$. Scan rate: $100 \mathrm{mV} \mathrm{s}{ }^{-1}$. Geometric surface area $1 \mathrm{~cm}^{2} . \Gamma=1$ corresponds to $10^{15}$ molecules $\mathrm{IrO}_{2} \mathrm{~cm}^{-2}$.

oxygen evolution is a slow reaction on diamond, the oxidation of organic compounds can occur with very high current efficiency under high overvoltage. As a corollary, however, the required extreme working conditions lead to high energy consumption. With the aim of reducing the overvoltage for the oxidation of organic substances, $\mathrm{IrO}_{2}$ nanoparticles were deposited on a diamond surface. The oxidation of oxalic acid was investigated, both on $\mathrm{BDD}_{\text {mild }}$ and on $\mathrm{BDD}-\mathrm{IrO}_{2}$
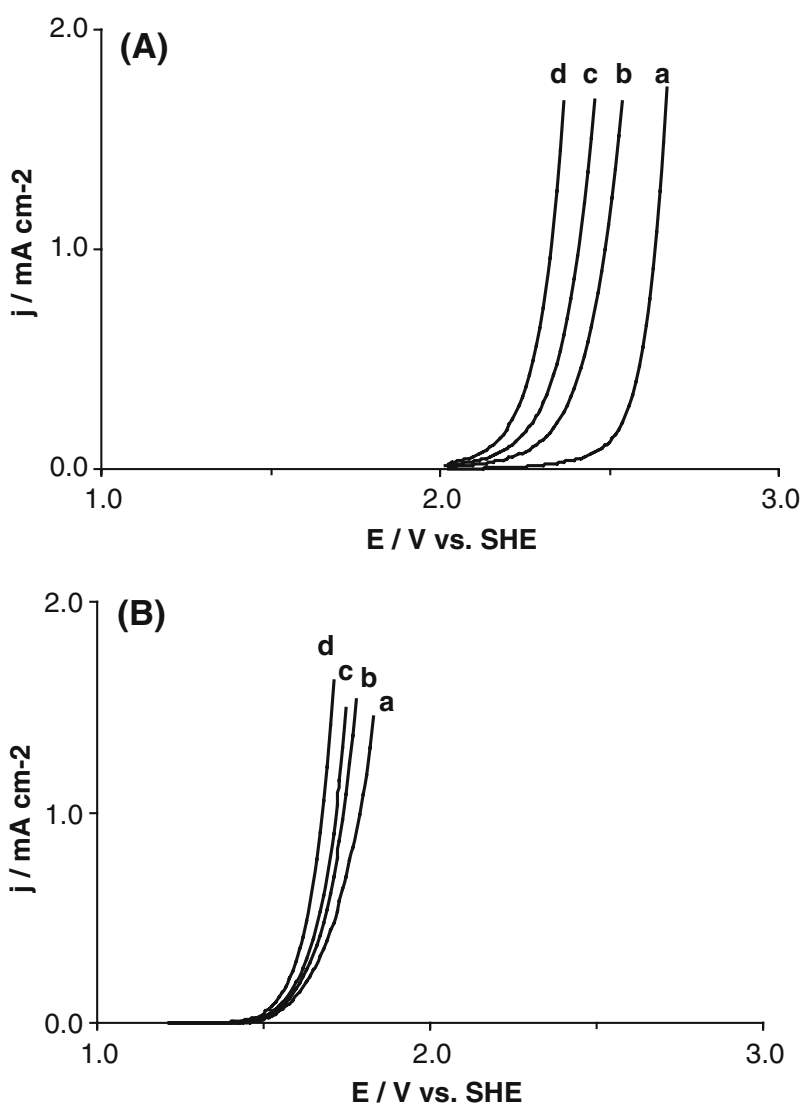

Fig. 4. Polarisation curves recorded at (A) BDD electrode and at (B) BDD- $\mathrm{IrO}_{2}$ electrode $(\Gamma=6.4)$ in $0.5 \mathrm{M} \mathrm{H}_{2} \mathrm{SO}_{4}$ containing oxalic acid in different concentrations; a: $0 \mathrm{M}$, b: $0.1 \mathrm{M}$, c: $0.2 \mathrm{M}$, d: $0.5 \mathrm{M}$. Scan rate: $20 \mathrm{mV} \mathrm{s}^{-1} . \Gamma=1$ corresponds to $10^{15}$ molecules $\mathrm{IrO}_{2} \mathrm{~cm}^{-2}$.
$(\Gamma=6.4)$ electrodes (Fig. 4). At both BDD and $\mathrm{BDD}-\mathrm{IrO}_{2}$ electrodes, the organic oxidation occurred in the potential region of water decomposition. As seen above (Fig. 3), the overpotential of water discharge on diamond decreased by about $1 \mathrm{~V}$ upon $\mathrm{IrO}_{2}$ deposition. Similar behaviour was found in the organic oxidation processes (Fig. 4). Such a negative shift of the anode potential occurring in the presence of organic compounds was found at both BDD and at $\mathrm{BDD}-\mathrm{IrO}_{2}$ electrodes. Bare diamond was found to be more sensitive in this respect. For instance, the potential shifts were more important on $\mathrm{BDD}$ than on $\mathrm{BDD}-\mathrm{IrO}_{2}$ at a given concentration of oxalic acid. This potential shift indicates involvement of intermediates formed during water decomposition in the organic oxidation process. The more significant shift on diamond electrodes can be explained in terms of the higher reactivity of the intermediates formed.

As previously explained [8], hydroxyl radicals are formed on diamond as intermediates of water decomposition under high overvoltage and undergo weak physical adsorption on the non-active electrode surface. The high reactivity of hydroxyl radicals leads to high current efficiency of organic oxidation reactions, while the OER remains a side reaction on BDD. The strong chemical bond formed between the hydroxyl radicals and the active sites of active electrodes such as $\mathrm{IrO}_{2}$ (formation of $\mathrm{IrO}_{3}$ ) decreases the overvoltage for OER, which becomes the main electrode process. However, intermediates are less reactive toward the organic substance and electrochemical oxidation of the organic compounds on $\mathrm{BDD}-\mathrm{IrO}_{2}$ takes place with low current efficiency. The surface activity of BDD electrodes was increased by deposition of $\mathrm{IrO}_{2}$ nanoparticles on the diamond surface. Cyclic voltammetry provided an insight into the surface redox transitions due to the redox couples $\operatorname{Ir}(\mathrm{III}) /(\mathrm{II})$ and $\operatorname{Ir}(\mathrm{IV}) / \operatorname{Ir}(\mathrm{III})$ being electroactive at different potentials. The surface capacitance calculated from cyclic voltammetry provided a measure of the active surface area of the electrodes, which depends on the $\mathrm{IrO}_{2}$ loading. The electrochemical behaviour of the electrodes was also tested in the presence of the outer-sphere redox couple $\left(\mathrm{Fe}(\mathrm{CN})_{6} \mathrm{III} /\right.$ II, and the electrocatalytic activity towards this reaction was increased by the deposition of $\mathrm{IrO}_{2}$ nanoparticles on the diamond surface. Similar to the case of inner-sphere reactions discussed above, the strong interaction between the electrode material and the hydroxyl radicals formed during water discharge leads to formation of a higher oxide $\left(\mathrm{IrO}_{3}\right)$ and influences the behaviour of BDD- $-\mathrm{IrO}_{2}$ electrodes towards oxygen evolution and oxidation of organic compounds. The overpotential for OER decreases while the organic oxidation process is kinetically hindered due to mediation of the poorly reactive surface redox system $\mathrm{IrO}_{3} / \mathrm{IrO}_{2}$. Surface-modified diamond electrodes can be considered as a diamond matrix in which particles are deposited more or less homogeneously. The reaction takes place on diamond as well as on the active sites offered by the deposited $\mathrm{IrO}_{2}$ 
particles. A distinct reaction rate constant can be associated to both processes. However, the reaction is much faster on the deposited $\mathrm{IrO}_{2}$ nanoparticles than on diamond. The effect is so strong that even with very small amounts deposited the activity of BDD is completely masked, and the observed behaviour can be attributed solely to the properties of the deposited $\mathrm{IrO}_{2}$.

\subsection{Thermally decomposed $A u$}

Gold deposits prepared with a sputtering time of 6 and $12 \mathrm{~s}$ (equivalent to $9.6 \times 10^{15}$ and $1.9 \times 10^{16}$ gold atom per $\mathrm{cm}^{2}$ geometric surface area, respectively) and then heated at $600{ }^{\circ} \mathrm{C}$ for $1 \mathrm{~h}$ in air were investigated. Heat treatment of as-sputtered gold gave rise to the formation of a stable population of gold nanoparticles. These nanoparticles were the result of surface migration and agglomeration of fine as-sputtered primary particles, without any loss of deposited gold, as confirmed by AAS analysis after dissolution of the deposits. The morphology of these two gold deposits on BDD was investigated by SEM (Fig. 5A, B). The average particle diameter is strongly dependent on the amount of sputtered gold deposited. In the domain of well dispersed deposits [18], the higher the deposited amount,
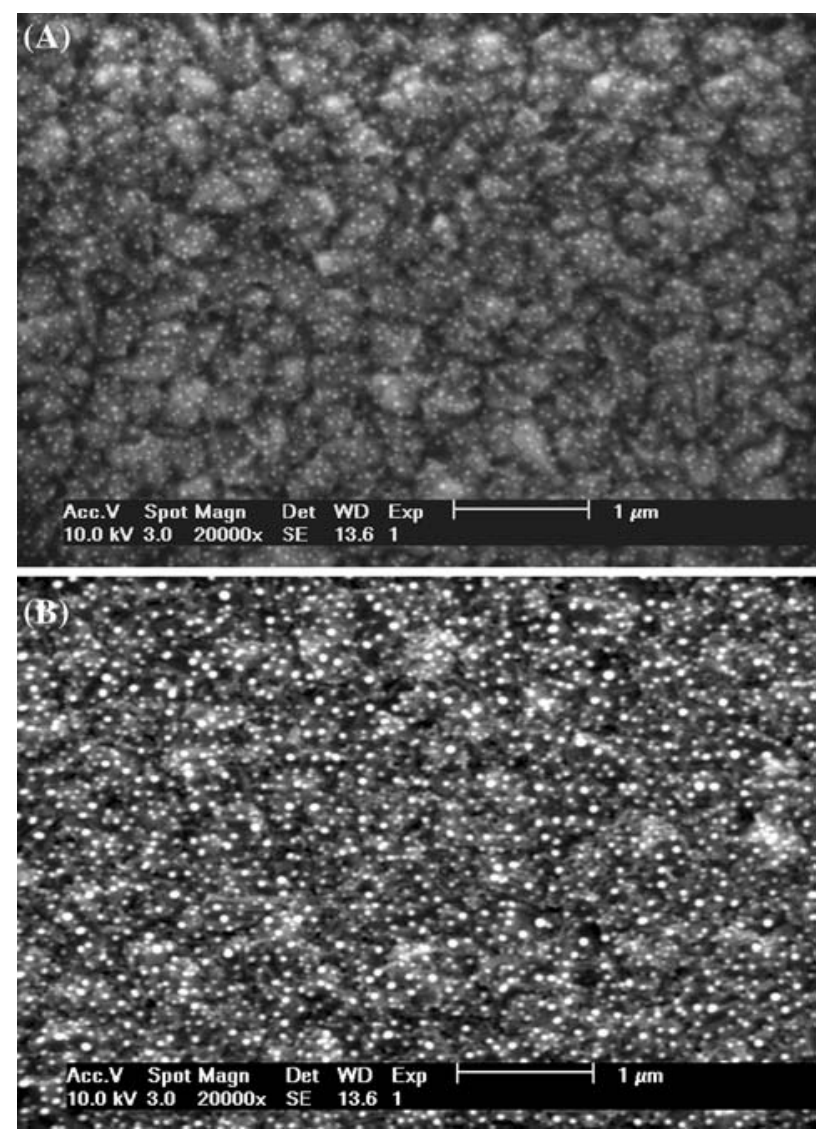

Fig. 5. SEM pictures of gold deposits on polycrystalline BDD substrate heated at $600{ }^{\circ} \mathrm{C}$ as a function of the deposited amount of gold: (A) $9.6 \times 10^{15}$, and (B) $1.9 \times 10^{16}$ gold atom per $\mathrm{cm}^{2}$ geometrical surface area, obtained with sputtering times of 6 and $12 \mathrm{~s}$, respectively. the larger the average size of nanoparticles (about 15 and $35 \mathrm{~nm}$ for sputtering times of 6 and $12 \mathrm{~s}$, respectively), while the particle density decreased only very slightly with increased loading. This latter observation indicates that gold nanoparticles grow essentially on specific surface sites, such as grain boundaries, defects, dislocations and impurities at the polycrystalline BDD surface.

In order to prove the stability of these nanoparticles, prolonged cyclic voltammetry was performed in $0.5 \mathrm{M}$ $\mathrm{H}_{2} \mathrm{SO}_{4}$ at a scan rate of $100 \mathrm{mV} \mathrm{s}{ }^{-1}$ and $25^{\circ} \mathrm{C}$ between potential limits of 0.64 and $1.8 \mathrm{~V}$. Under these conditions, the voltammetric signals of the BDD-Au electrodes remained unchanged even after 1000 cycles and no marked decrease in the charge of gold oxides reduction peak (270 and $382 \mu \mathrm{C} \mathrm{cm}^{-2}$ for 6 and $12 \mathrm{~s}$ deposition times, respectively) was noticed [18]. This allows the use of these nanoparticles for the electrochemical reduction of oxygen and, therefore, their electrocatalytic activity towards the oxygen reduction reaction (ORR) was investigated. Figure 6 shows the voltammetric curves of bulk $\mathrm{Au}$ and $\mathrm{BDD}-\mathrm{Au}$ electrodes in $0.5 \mathrm{M} \mathrm{H}_{2} \mathrm{SO}_{4}$ solution saturated with oxygen. The peak visible on all signals is attributed to electrocatalytic reduction of oxygen. The current density was plotted with respect to the geometric area of the gold deposit. The estimation of the total area of gold nanoparticles is based on SEM observation and on determination of the Au loading by AAS. Several assumptions were made to perform this evaluation: (i) all particles are of identical spherical shape and size, (ii) they have a face-centred cubic (fcc) structure like the bulk gold lattice, implying a packing density of $74 \%$, and (iii) the contact surface between particles and the diamond substrate can be neglected. In the case of the bulk gold electrode, a well-defined cathodic peak appeared at a potential of approximately $-0.034 \mathrm{~V}$, with a current density of $0.6 \mathrm{~mA} \mathrm{~cm}$. The use of BDDsupported gold nanoparticles causes a positive shift of

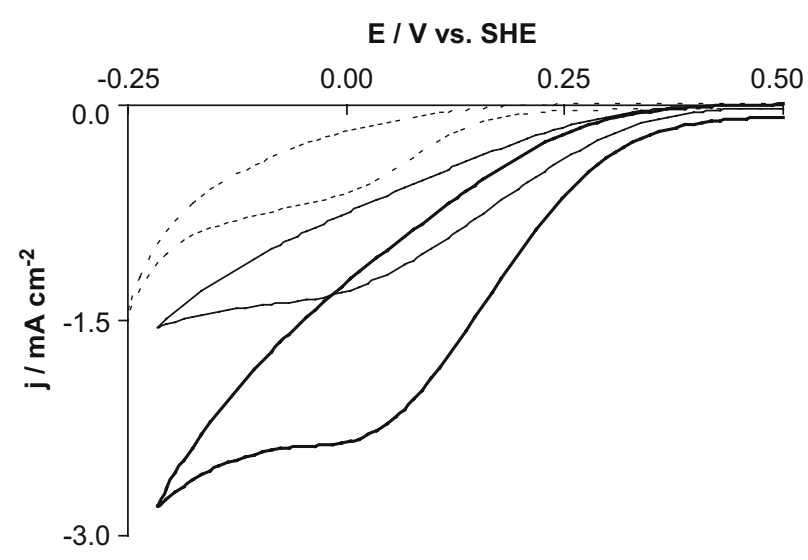

Fig. 6. Cyclic voltammograms in $\mathrm{O}_{2}$-saturated $0.5 \mathrm{M} \mathrm{H}_{2} \mathrm{SO}_{4}$ solution of a bulk gold electrode (dashed line) and gold nanoparticles deposited on BDD, with $9.6 \times 10^{15}$ (thick solid line) and $1.9 \times 10^{16}$ (thin solid line) gold atom per $\mathrm{cm}^{2}$ geometrical surface area. Scan rate: $100 \mathrm{mV} \mathrm{s}^{-1}$. 
the peak potential to 0 and $+0.015 \mathrm{~V}$ (for particles prepared by 12 and $6 \mathrm{~s}$ sputtering times, respectively). Moreover, the current density increases up to values of 1.25 and $2.34 \mathrm{~mA} \mathrm{~cm}^{-2}$ on these particles (mean diameter of 35 and $15 \mathrm{~nm}$, respectively). The catalytic efficiency of gold nanoparticles (6 s sputtering time) was four times larger than that of the bulk gold electrode and the hydrogen evolution is onset at more negative potentials on the BDD-Au nanodeposits, which makes oxygen reduction well defined.

\subsection{Electrodeposited Pt particles}

The electrodeposition of $\mathrm{Pt}$ particles on a BDD electrode was performed by applying a potential step to a deaerated $2 \mathrm{~mm} \mathrm{H}_{2} \mathrm{PtCl}_{6}$ solution in $1 \mathrm{M} \mathrm{HClO}_{4}$. The potential was shifted from an equilibrium potential $(1 \mathrm{~V}$, where no reduction of platinic ions takes place) to a potential at which the reduction of $\mathrm{Pt}^{4+}$ to metallic $\mathrm{Pt}$ occurs $(0.02-0.15 \mathrm{~V})$. The electrodeposition mechanism was studied by means of chronoamperometry. Figure 7 shows a typical current vs. time profile for a potentiostatic step experiment, with a potential step from $+1 \mathrm{~V}$ to $+0.02 \mathrm{~V}$. This chronoamperometric curve is very close to the theoretical one for electrochemical deposition [47], and can be divided into four successive welldefined time intervals as illustrated in Fig. 7. At the beginning of the first interval (zone I), a sharp increase, followed by a current decay, is observed, corresponding to the double-layer charging current and the initial nucleation process. Free growth of independent nuclei and formation of new nucleation sites without overlapping effects explain the current increase of the second interval (zone II). During the third interval (zone III), the growth of independent nuclei and their overlap can occur simultaneously; the current increases up to a maximum $\left(j_{\mathrm{m}}\right)$ at which nuclei overlapping occurs. Finally, during the fourth interval (zone IV) the current

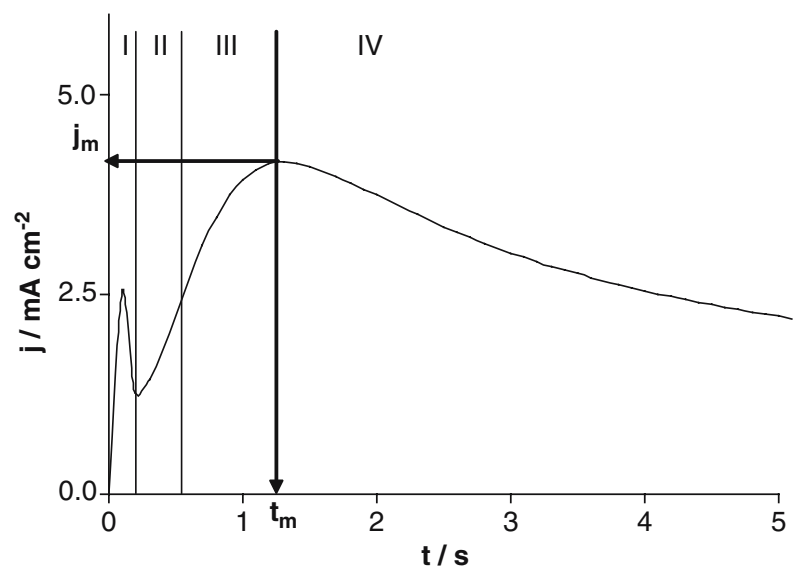

Fig. 7. Chronoamperometric curve of the electrodeposition of platinum on a BDD electrode. Potential step from +1 to $+0.02 \mathrm{~V}$ in $2 \mathrm{mM} \mathrm{H}_{2} \mathrm{PtCl}_{6}+1 \mathrm{M} \mathrm{HClO}_{4}$ solution, $T=25^{\circ} \mathrm{C}$. The different deposition time intervals are marked (zones I-IV) as well as the maximum current density $\left(j_{\mathrm{m}}\right)$ and the corresponding maximum time $\left(t_{\mathrm{m}}\right)$ (see text). decreases due to the overlapping of the diffusion zones of different nuclei and to their coalescence. From the time $t_{\mathrm{m}}$ corresponding to $j_{\mathrm{m}}$, the current decreases due to the decrease in the surface area of deposited platinum particles, and it can be considered that a change from hemispherical to linear mass transfer diffusion occurs because of the increase in particle size.

In the domain of free growth of nuclei (zone II), the $I^{1 / 2}$ vs. $t$ plot is linear. This indicates a 3D-nucleation process of hemispherical nucleus with diffusion control [47]. On the basis of this behaviour, Sharifker and Hills [48] have developed a model that allows to distinguish between instantaneous and progressive mechanism of nucleation. In the instantaneous nucleation mechanism, all nuclei are rapidly created during the first stages of the process and their number remains constant throughout growth. In the progressive nucleation mechanism, new nuclei are continuously formed during the whole deposition process because the nucleation rate is low. Figure 8 compares the experimental $I-t$ curve (curve a) with those relative to the two limiting mechanisms (curve $\mathrm{b}$ and $\mathrm{c}$ for progressive and instantaneous nucleation, respectively). The experimental curve of Fig. 8 agrees better with that of the progressive nucleation mechanism. Similar results have been obtained for the electrodeposition of platinum on graphite [49]. Figure 9 shows SEM micrographs of a BDD-Pt electrode prepared by performing a potential step from $1 \mathrm{~V}$ to $0.02 \mathrm{~V}$ in a $2 \mathrm{mM} \mathrm{H}_{2} \mathrm{PtCl}_{6}+1 \mathrm{M} \mathrm{HClO}_{4}$ solution for $5 \mathrm{~s}$. Spherical and isolated particles are observed with a quite large size variation that covers the $40-700 \mathrm{~nm}$ range. This is indicative of continuous formation of new nuclei during deposition and is in agreement with the progressive mechanism of nucleation of $\mathrm{Pt}$ on BDD.

A typical cyclic voltammogram (CV) for electrodeposited Pt particles on BDD is shown in Fig. 10. This voltammogram exhibits the characteristic feature of $\mathrm{Pt}$,

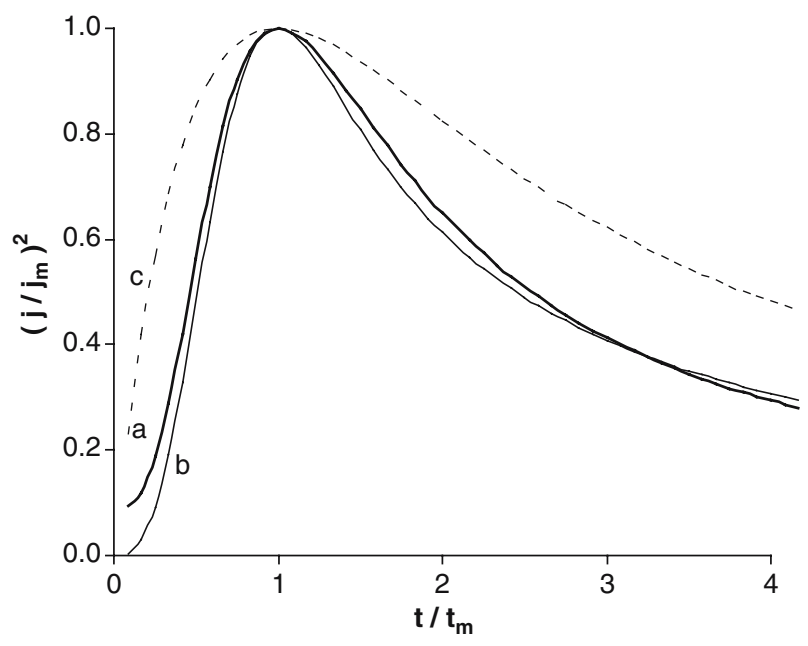

Fig. 8. $I-t$ response plotted with reduced variables; $j_{\mathrm{m}}$ and $t_{\mathrm{m}}$ as shown in Figure 7. (a) Experimental values. (b) Theoretical data for progressive nucleation [48]. (c) Theoretical data for instantaneous nucleation [48]. 

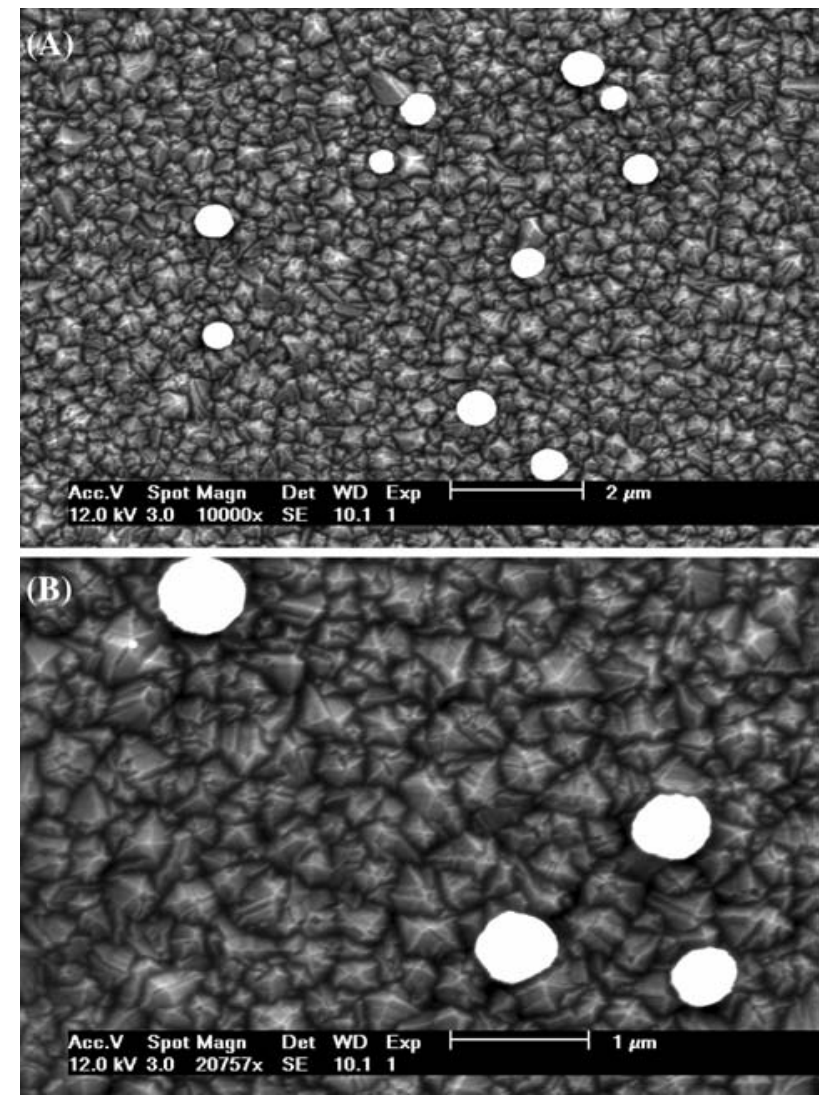

Fig. 9. SEM pictures at two different magnification scales of a BDD-Pt electrode prepared by electrodeposition with a single potential step (5 s) from 1 to $0.02 \mathrm{~V}$ in a $\mathrm{N}_{2}$-saturated $2 \mathrm{~mm}_{2} \mathrm{HtCl}_{6}+$ $1 \mathrm{M} \mathrm{HClO}_{4}$ solution.

i.e. two distinctive $\mathrm{H}$ adsorption-desorption peaks between $0.05 \mathrm{~V}$ and $0.35 \mathrm{~V}$, followed by a fine doublelayer region corresponding to metallic Pt. Potential cycling at more anodic potentials, which induces $\mathrm{Pt}$ oxide formation (broad plateau), was not performed in order to avoid surface rearrangement [50] and aggregation of particles [51]. The electrochemical response of

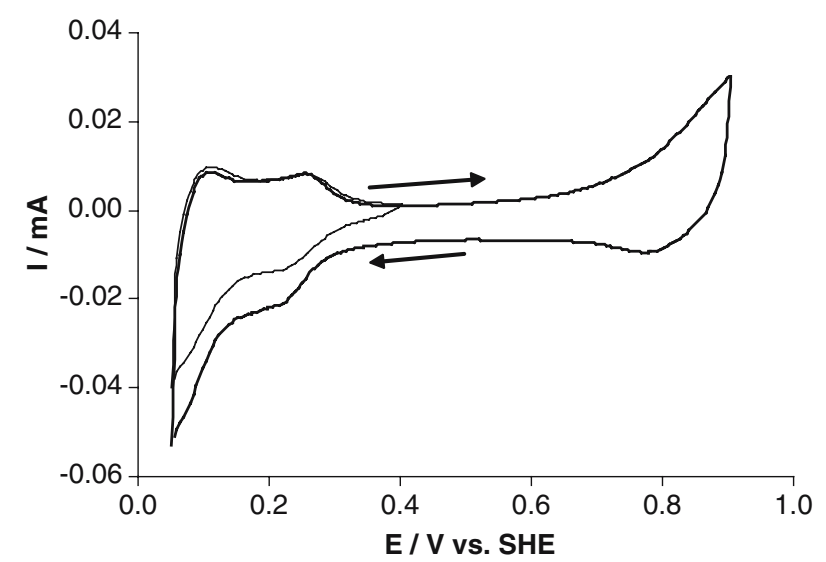

Fig. 10. Cyclic voltammograms of electrodeposited $\mathrm{Pt}$ particles on BDD electrode. Recorded in a $\mathrm{N}_{2}$-saturated $1 \mathrm{M} \mathrm{HClO}_{4}$ solution at $50 \mathrm{mV} \mathrm{s}{ }^{-1}$ and $25^{\circ} \mathrm{C}$. Conditions of electrodeposition: single potential step $(5 \mathrm{~s})$ from 1 to $0.02 \mathrm{~V}$ in a $\mathrm{N}_{2}$-saturated $2 \mathrm{~mm} \mathrm{H}_{2} \mathrm{PtCl}_{6}+$ $1 \mathrm{M} \mathrm{HClO}_{4}$ solution. this BDD-Pt composite electrode can be attributed solely to the deposited Pt particles, even at very low Pt loadings, due to the chemical inertness and low background current of the diamond substrate. This justifies the choice of BDD for the electrochemical study of supported catalytic nanoparticles. Electrodeposited Pt particles have exhibited electrocatalytic activity (data not shown due to the large size of these particles) also toward methanol electrooxidation. The CV for methanol electrooxidation on electrodeposited $\mathrm{Pt}$ particles exhibits the characteristic features of methanol oxidation on Pt, i.e. two well-defined oxidation peaks occurring during the forward and the reverse scan. This unusual shape is related to the surface transitions occurring on $\mathrm{Pt}$ when the potential is cycled. Indeed, continuous dissociative adsorption and oxidation of methanol can only take place on a metallic $\left(\mathrm{Pt}^{0}\right)$ platinum surface free of adsorbed poison (CO). Equations 3-6 summarize the overall mechanism of methanol oxidation on $\mathrm{Pt}$ :

$$
\begin{aligned}
& 3 \mathrm{Pt}\left(\mathrm{H}_{2} \mathrm{O}\right)+\mathrm{CH}_{3} \mathrm{OH} \rightarrow \mathrm{Pt}_{3}\left(\mathrm{CH}_{3} \mathrm{OH}\right)_{\mathrm{ads}}+3 \mathrm{H}_{2} \mathrm{O} \\
& \mathrm{Pt}_{3}\left(\mathrm{CH}_{3} \mathrm{OH}\right)_{\mathrm{ads}} \rightarrow \mathrm{Pt}(\mathrm{CO})_{\mathrm{ads}}+2 \mathrm{Pt}+4 \mathrm{H}^{+}+4 \mathrm{e}^{-} \\
& \mathrm{Pt}+\mathrm{H}_{2} \mathrm{O} \rightarrow \mathrm{Pt}(\cdot \mathrm{OH})_{\mathrm{ads}}+\mathrm{H}^{+}+\mathrm{e}^{-} \\
& \mathrm{Pt}(\mathrm{CO})_{\mathrm{ads}}+\mathrm{Pt}(\cdot \mathrm{OH})_{\mathrm{ads}} \rightarrow 2 \mathrm{Pt}+\mathrm{CO}_{2}+\mathrm{H}^{+}+\mathrm{e}^{-}
\end{aligned}
$$

Although electrodeposited Pt particles on BDD are efficient for methanol electrooxidation, their size domain is so broad that they cannot be strictly classified as nanoparticles. The literature attributes this heterodispersity to the inhomogeneous nature of the BDD substrates [24], mainly to the presence of non-diamond $\mathrm{sp}^{2}$ impurities that act as preferential deposition sites. Therefore, a "size-effect" cannot be reasonably expected in this case, and some alternative synthesis techniques have to be employed to deposit real Pt nanoparticles on BDD.

\subsection{Pt nanoparticles prepared by the dendrimeric method}

The use of dendrimers, in particular polyamidoamine (PAMAM) amine-terminated dendrimer of 4 th generation $\left(\mathrm{G} 4-\mathrm{NH}_{2}\right)$ may offer a unique path to rational design and synthesis of nanostructured electrocatalysts. In fact, this family of dendrimers can exchange metal ions into their branches. Subsequent reduction in solution yields metal (M) dendrimer encapsulated nanoparticles (M DENs). 
The M DENs composite materials are prepared by mixing aqueous solutions containing dendrimers and metal ions such as $\mathrm{Pt}^{4+}$. These metal ions penetrate into the dendrimer interior where they complex strongly with internal tertiary amine groups. Reduction of dendrimer/ metal-ion composites with an excess of a chemical reducing agent (usually $\mathrm{NaBH}_{4}$ ) yields monodisperse, intradendrimer nanoparticles. Figure 11 shows a schematic presentation of the preparation of dendrimerencapsulated $\mathrm{Pt}$ nanoparticles (Pt DENs). A TEM micrograph of a Pt DENs sample is shown in Fig. 12 with the related size distribution. $\mathrm{A} \mathrm{Pt}^{4+} / \mathrm{G}_{4}-\mathrm{NH}_{2}$ molar ratio of 30 characterizes this sample. The particles have diameters in the 1.5-4 nm range with an average of $2.5 \pm 1 \mathrm{~nm}$.

The Pt DEN nanoparticles deposited onto the BDD surface were covered by a Nafion layer as described previously, and then treated in air at $425{ }^{\circ} \mathrm{C}$ for $4 \mathrm{~h}$ followed by a treatment in $\mathrm{H}_{2}$ at $100{ }^{\circ} \mathrm{C}$ for $1 \mathrm{~h}$. This heat treatment is used in order to remove the dendrimer template and to liberate the Pt nanoparticles. The use of

1)

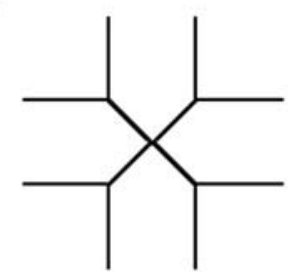

2)
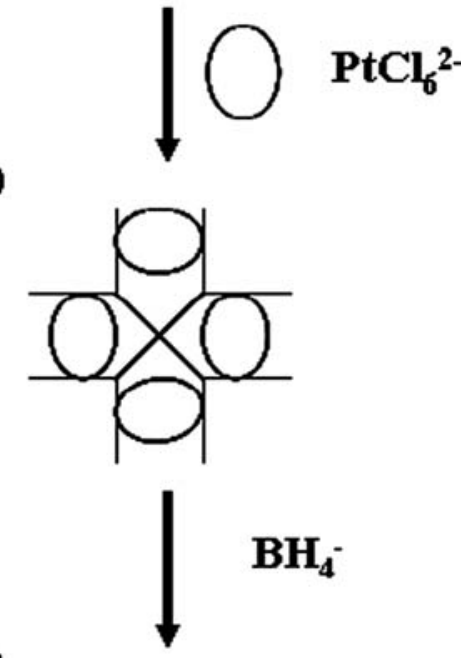

3)

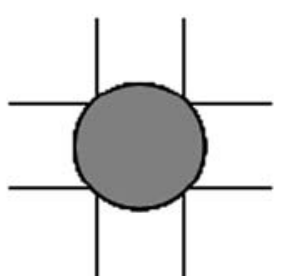

Fig. 11. Schematic principle of the synthesis of $\mathrm{Pt}$ nanoparticles via the dendrimer method. (1): mixing of dendrimer and $\mathrm{H}_{2} \mathrm{PtCl}_{6}$ aqueous solutions, (2): formation of a dendrimer-platinic complex ion and (3): reduction of $\mathrm{Pt}^{4+}$ in $\mathrm{Pt}^{0}$, nucleation and growth of nanoparticles within the interior of the dendrimer by addition of $\mathrm{NaBH}_{4}$.
BDD supports can allow stabilization (via avoiding aggregation) of the Pt nanoparticles after removal of the dendrimer template by heat treatment.

Cyclic voltammetry in $1 \mathrm{M} \mathrm{HClO}_{4}$ of the BDDsupported $\mathrm{Pt}$ nanoparticles prepared by the described dendrimeric method showed the well-known characteristic voltammorgam of Pt. However, this technique has shown a limited reproducibility and needs further improvement.

\subsection{Microemulsion-synthesized Pt/Ru nanoparticles}

This method consists in the preparation of a water-in-oil microemulsion containing the metallic precursors (Pt or $\mathrm{Ru}$ salt) dissolved in the aqueous phase using $\mathrm{n}$-heptane as the oil phase, then a reducing agent (solid $\mathrm{NaBH}_{4}$ ) is introduced into this microemulsion. For the preparation of alloyed nanoparticles, a microemulsion with an aqueous phase containing a convenient atomic proportion of the two alloying elements was used. Figure 13 shows a schematic presentation of this technique. It involves the following steps: (1) mixing of the microemulsion with solid sodium borohydride, (2) nucleation and (3) growth of the particles inside the inverse micelles. The surfactant layer, which stabilizes the aqueous dispersion in the organic solvent, will stop the growth. Nucleation and growth are initiated by the reduction of the metallic precursors by $\mathrm{NaBH}_{4}$, according to Equations (7) and (8):

$$
\begin{aligned}
\mathrm{H}_{2} \mathrm{PtCl}_{6}+\mathrm{NaBH}_{4}+3 \mathrm{H}_{2} \mathrm{O} \rightarrow & \mathrm{Pt}+\mathrm{H}_{3} \mathrm{BO}_{3}+5 \mathrm{HCl} \\
& +\mathrm{NaCl}+2 \mathrm{H}_{2}
\end{aligned}
$$

$$
\begin{aligned}
\mathrm{RuCl}_{3}+\mathrm{NaBH}_{4}+3 \mathrm{H}_{2} \mathrm{O} \rightarrow & \mathrm{Ru}+\mathrm{H}_{3} \mathrm{BO}_{3}+2 \mathrm{HCl} \\
& +\mathrm{NaCl}+5 / 2 \mathrm{H}_{2}
\end{aligned}
$$

$\mathrm{Pt} / \mathrm{Ru}$ nanoparticles of different compositions have been synthesized by mixing appropriate ratios of $\mathrm{Pt}$ and $\mathrm{Ru}$ precursors in the aqueous phase of the microemulsion. TEM micrographs of $\mathrm{Pt} / \mathrm{Ru}$ nanoparticles of different compositions are shown in Fig. 14. Size distributions are similar for all samples, indicating that the size of the resulting particles is determined by the microemulsion formulation and not by the composition of the aqueous phase. Moreover, the size domain of these particles is limited to the $2-5 \mathrm{~nm}$ range and the mean diameter was in all cases about $2-3 \mathrm{~nm}$, corresponding well to the commonly accepted definition of a nano-object in electrocatalysis.

The suitability of the microemulsion method for the synthesis of binary nanoparticles of controlled composition was checked by means of XPS. XPS results are summarized in Table 2, together with EDX results processed simultaneously with TEM measurements. The effective composition of nanoparticles is very close to the nominal value, i.e. the composition of the nanoparticles can be controlled with a very good 

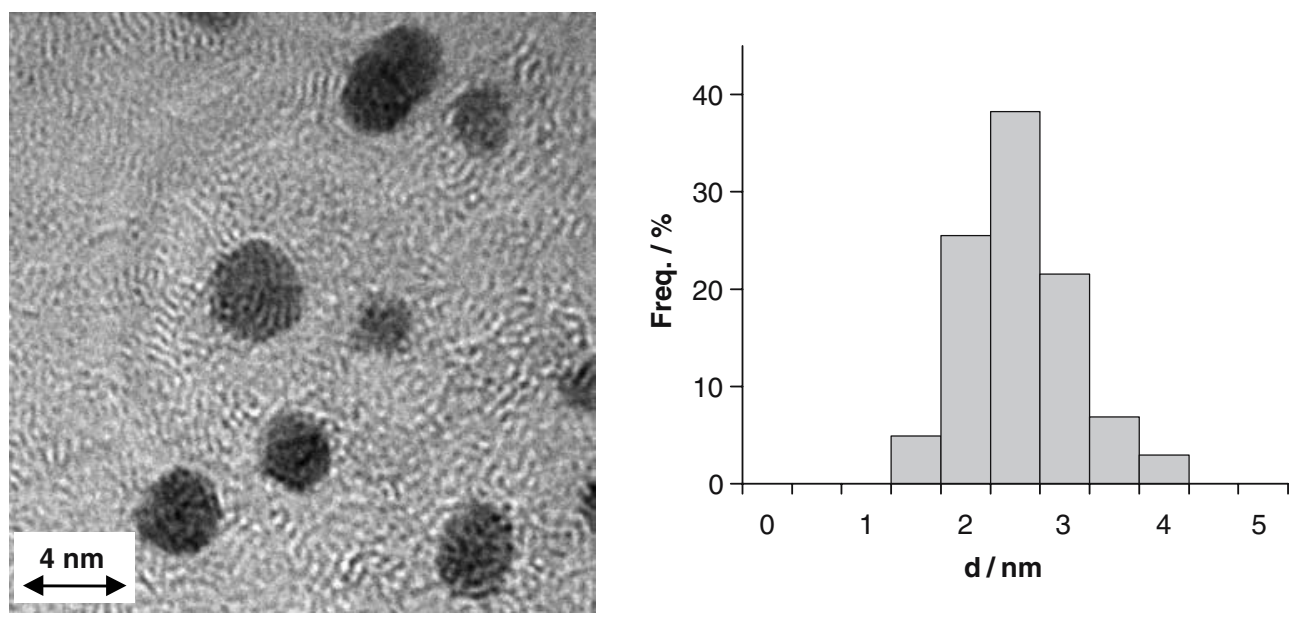

Fig. 12. TEM micrograph and size distribution of $\mathrm{Pt}$ DENs synthesized by the dendrimeric method. $\mathrm{Pt}^{4+} / \mathrm{G}_{4}-\mathrm{NH}_{2}$ molar ratio adjusted to 30 .

accuracy by adjusting the composition of the microemulsion aqueous phase. XPS was also used to evaluate the electronic effect between $\mathrm{Pt}$ and Ru. Figure 15 shows the chemical shift of the $\mathrm{Pt} 4 f_{7 / 2}\left(\mathrm{Pt}^{0}\right)$ peak in $\mathrm{Pt} / \mathrm{Ru}$ nanoparticles. Due to the presence of $\mathrm{Ru}$ this peak is displaced to lower binding energies. This is indicative of transfer of $\mathrm{d}$ electrons from $\mathrm{Ru}$ to Pt. Consequently, the electronic properties of $\mathrm{Pt}$ are modified and the $\mathrm{Pt}-\mathrm{CO}$ bond can be weakened, facilitating the poison removal [52]. However, the energy shift is weak, due to the low difference in electronegativity of the two metals. There-

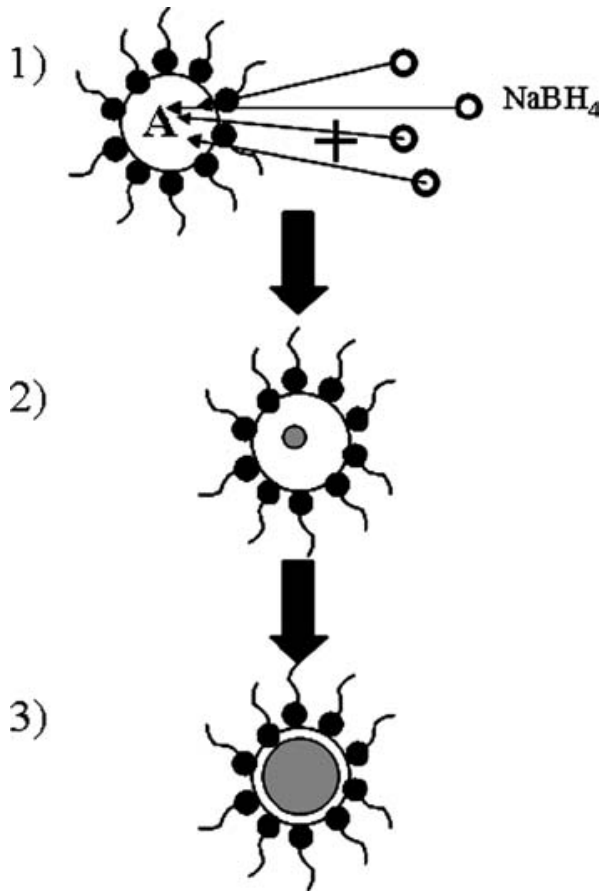

Fig. 13. Schematic principle of the synthesis of Pt and Pt-based alloy nanoparticles via the microemulsion method. (1): mixing of the microemulsion with solid sodium borohydride that will diffuse into the aqueous nanodroplets, (2): nucleation and (3): growth of particles inside the inverse micelles. A: aqueous phase, composed by mixtures of metallic precursors $\left(\mathrm{H}_{2} \mathrm{PtCl}_{6}+\mathrm{RuCl}_{3}\right)$ in appropriate ratios in order to yield the desired binary Pt-based nanoparticles. fore, enhancement of electrocatalytic activity of $\mathrm{Pt} / \mathrm{Ru}$ nanoparticles compared to that of Pt nanoparticles may not be attributed solely to the electronic effect. The effectiveness of alloying between $\mathrm{Pt}$ and $\mathrm{Ru}$ is illustrated in Fig. 16, which shows the XRD displacement of the $\mathrm{Pt}(111)$ and (200) reflections of $\mathrm{Pt}, \mathrm{Pt}_{80} \mathrm{Ru}_{20}$ and $\mathrm{Pt}_{50} \mathrm{Ru}_{50}$ nanoparticles deposited on BDD. The band displacement indicates a decrease in the sample lattice parameter, and it is characteristic of a $\mathrm{Pt} / \mathrm{Ru}$ alloy formation [53]. A gradual loss of crystallinity occurs when the Ru content in the particles is increased, and it can be attributed to the presence of increasing amounts of Ru in the amorphous state. The XRD results indicate that, in addition to the alloy formation between Pt and $\mathrm{Ru}$ evidenced by band displacement, regions may exist where $\mathrm{Ru}$ is not alloyed with Pt but is only present in its amorphous state [53].

Obviously, XPS cannot be considered as a surface analysis tool for the study of objects as small as $2-3 \mathrm{~nm}$, since their whole depth is responding. Cyclic voltammetry can provide much more information on the surface state of BDD-supported nanoparticles. Figure 17 shows, as typical examples, $\mathrm{CV}$ in pure supporting electrolyte $\left(1 \mathrm{M} \mathrm{HClO}{ }_{4}\right)$ of $\mathrm{Pt}, \mathrm{Pt}_{50} \mathrm{Ru}_{50}$ and $\mathrm{Ru}$ nanoparticles deposited on BDD. Two major tendencies can be observed when the $\mathrm{Ru}$ content in the particles is increased: (i) decrease in the quality of the $\mathrm{H}$ adsorption-desorption feature, and (ii) increase in the background current in the double-layer region. This is indicative of gradual transition from dominating $\mathrm{Pt}$ surface character to dominating $\mathrm{Ru}$ surface character. This is quite informative in the sense that the more efficient nanoparticles for the electrocatalysis of methanol oxidation can be discriminated. Indeed, $\mathrm{Pt}$ is the only metal capable of alcohol dehydrogenation, at least at room temperature.

Figure 18 shows the specific molar current for methanol oxidation recorded by $\mathrm{CV}$ as a function of the $\mathrm{Pt}$ content in the particles. As a general trend, the specific molar oxidation current decreases with the Pt content in the particles. Indeed, the decrease in the Pt content in 


\begin{tabular}{|c|c|c|c|}
\hline A & XPS and ED & Pt/Ru n & termined by \\
\hline 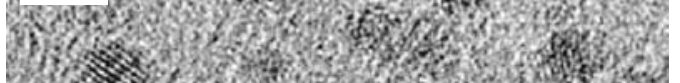 & $\begin{array}{l}\text { Nominal Pt } \\
\text { content } / \text { at } \%\end{array}$ & $\begin{array}{l}\text { XPS Pt } \\
\text { content } / a t \%\end{array}$ & $\begin{array}{l}\text { EDX Pt } \\
\text { content } / \text { at } \%\end{array}$ \\
\hline 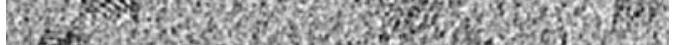 & 100 & 100 & 100 \\
\hline$x$ ryser & 80 & 78.9 & 84 \\
\hline $33 \mathrm{~g}-\mathrm{n}$ - & 60 & 58 & 61.7 \\
\hline 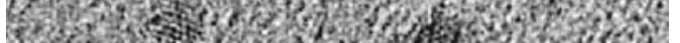 & 50 & 50 & 53.6 \\
\hline 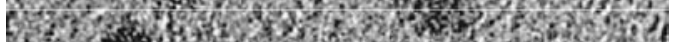 & 40 & 39.9 & 36.8 \\
\hline 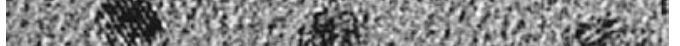 & 20 & 21.7 & 16.5 \\
\hline 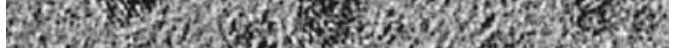 & 0 & 0 & 0 \\
\hline
\end{tabular}

clearly be observed in Fig. 19, which shows the linear sweep voltammograms and the onset of methanol oxidation on $\mathrm{Pt}$ and $\mathrm{Pt}_{80} \mathrm{Ru}_{20}$ nanoparticles. The onset of methanol oxidation is significantly shifted to lower potentials on the bimetallic surface. For instance, in the case of methanol oxidation, a potential of $0.51 \mathrm{~V}$ is needed to reach a specific molar current of $50 \mathrm{~A}$ $\mathrm{mol}^{-1}$ met at $\mathrm{Pt}$, whereas a value of $0.43 \mathrm{~V}$ is sufficient at $\mathrm{Pt}_{80} \mathrm{Ru}_{20}$. This indicates that continuous alcohol adsorption and dehydrogenation occur, i.e. surface $\mathrm{Pt}$ sites are available. It is concluded that on the bimetallic surface the surface reaction between adsorbed $\mathrm{CO}$ and oxygen-containing species occurs at lower potentials, and that the bifunctional mechanism is valid at $\mathrm{Pt} / \mathrm{Ru}$ nanoparticles.

Figure 20 shows the current vs. time transients for methanol oxidation on $\mathrm{Pt}$ and $\mathrm{Pt}_{80} \mathrm{Ru}_{20}$ nanoparticles, recorded at constant potentials of $0.4(\mathrm{~A})$ and $0.6 \mathrm{~V}(\mathrm{~B})$. These potentials are located before and after water activation on Pt. All current vs. time transients for methanol oxidation exhibit the same profile, i.e. sharp decrease in current followed by a plateau. This profile has already been reported in the literature and attributed to fast Pt surface poisoning by strongly adsorbed intermediates [54]. Some additional comments can be done, depending on the applied potential and the used

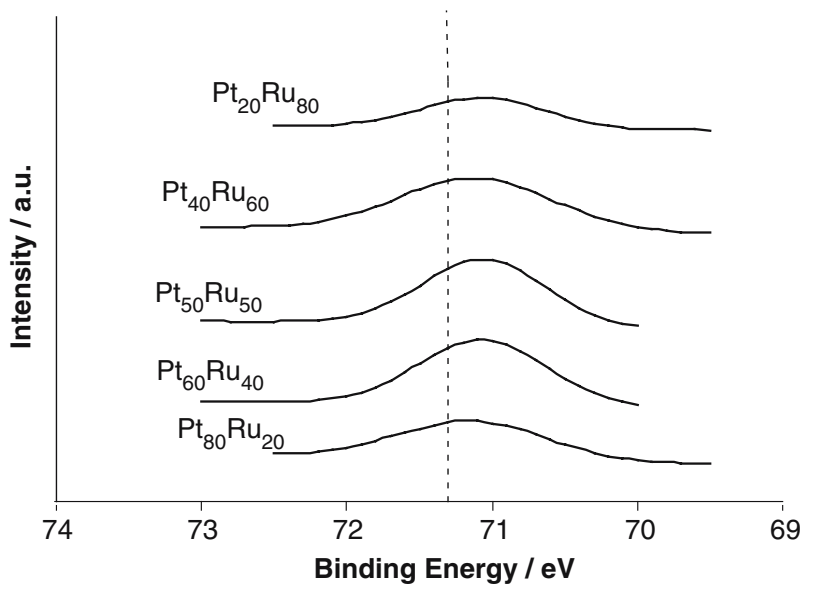

Fig. 15. Chemical shift of the XPS Pt $4 f_{7 / 2}\left(\mathrm{Pt}^{0}\right)$ line of bimetallic microemulsion-synthesized $\mathrm{Pt} / \mathrm{Ru}$ nanoparticles deposited on $\mathrm{Au}$ substrate. The dashed vertical line represents the position of the signal in pure Pt nanoparticles. highest specific molar current for methanol oxidation. However, the beneficial effect of $\mathrm{Ru}$ addition to $\mathrm{Pt}$ can
Fig. 14. TEM micrographs of $\mathrm{Pt} / \mathrm{Ru}$ nanoparticles synthesized by the microemulsion method. (A) $\mathrm{Pt}$ nanoparticles, (B) $\mathrm{Pt}_{50} \mathrm{Ru}_{50}$ nanoparticles, and (C) Ru nanoparticles.

the nanoparticles decreases concomitantly the probability of finding three adjacent $\mathrm{Pt}$ sites for methanol adsorption. This also explains why, within the samples synthesized here, $\mathrm{Pt}_{80} \mathrm{Ru}_{20}$ nanoparticles exhibit the 


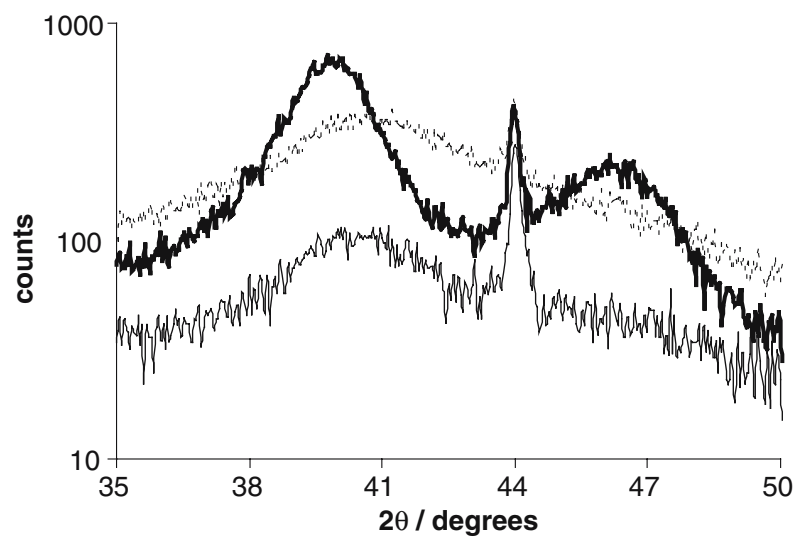

Fig. 16. XRD patterns of microemulsion-synthesized Pt (thick solid line), $\mathrm{Pt}_{80} \mathrm{Ru}_{20}$ (thin solid line) and $\mathrm{Pt}_{50} \mathrm{Ru}_{50}$ (thin dashed line) nanoparticles deposited on BDD.
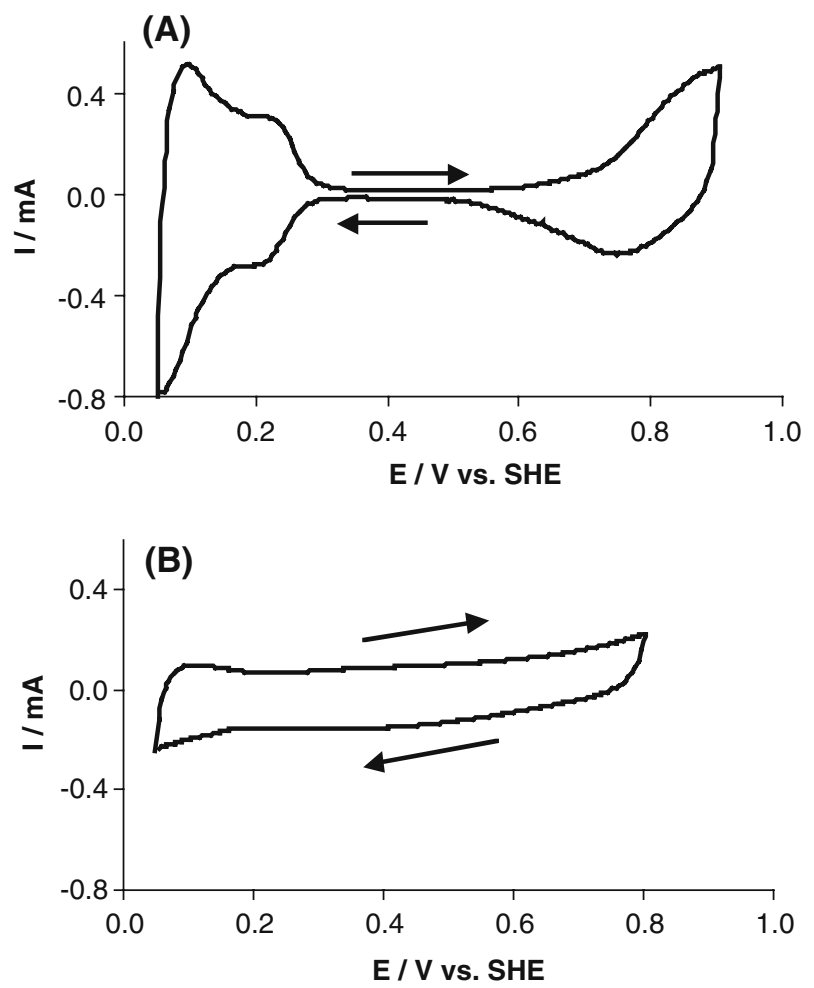

(C)

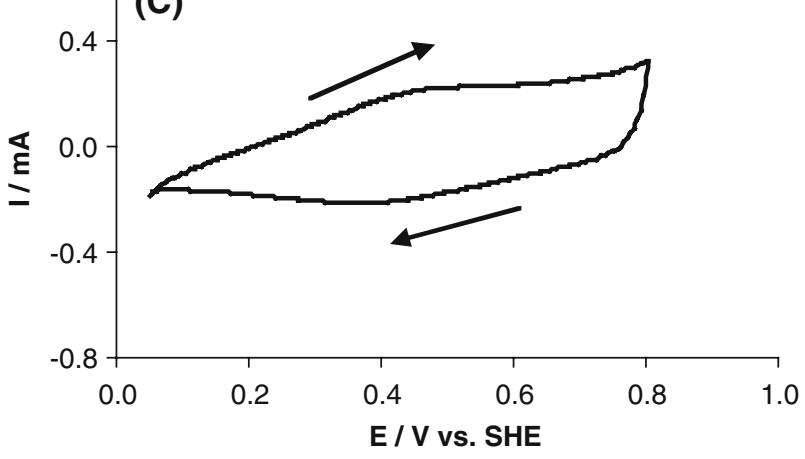

Fig. 17. $\mathrm{CV}$ of microemulsion-synthesized $\mathrm{Pt}(\mathrm{A}), \mathrm{Pt}_{50} \mathrm{Ru}_{50}$ (B) and $\mathrm{Ru}$ nanoparticles $(\mathrm{C})$ deposited on BDD. Recorded in $\mathrm{N}_{2}$-saturated $1 \mathrm{M} \mathrm{HClO}_{4}$ solution at $50 \mathrm{mV} \mathrm{s}{ }^{-1}$ and $25^{\circ} \mathrm{C}$.

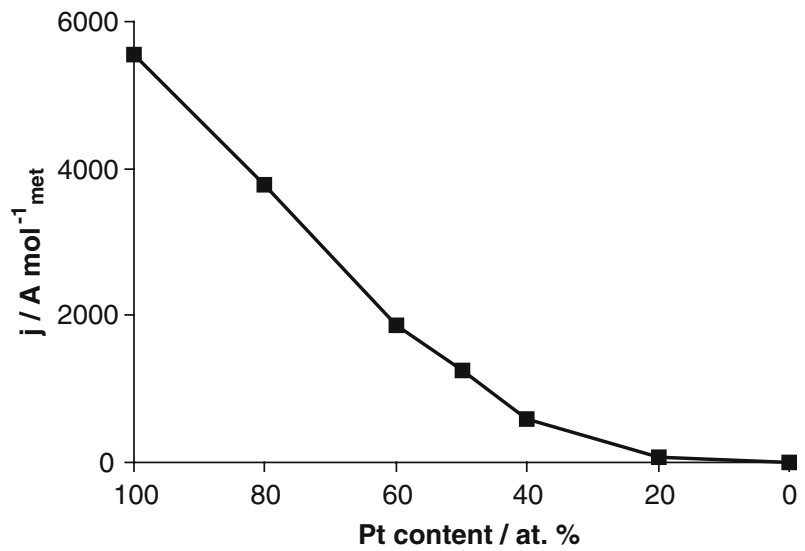

Fig. 18. Specific molar current of methanol electrooxidation obtained with $\mathrm{CV}$ measurements in $\mathrm{N}_{2}$-saturated $1 \mathrm{M} \mathrm{HClO}_{4}+0.1 \mathrm{M}$ $\mathrm{CH}_{3} \mathrm{OH}$ solution at $20 \mathrm{mV} \mathrm{s}-1$ and $25^{\circ} \mathrm{C}$.

catalytic surface. At $0.6 \mathrm{~V}$ (Fig. 20B), water discharge is activated on $\mathrm{Pt}$, and therefore free $\mathrm{Pt}$ catalytic sites are available for methanol dehydrogenation. This step is only possible on Pt sites, so that the initial specific molar current is higher on Pt nanoparticles than on bimetallic surfaces. The specific molar current then falls dramatically due to surface poisoning. The current decrease is far less pronounced on $\mathrm{Pt}_{80} \mathrm{Ru}_{20}$ nanoparticles indicating higher poison tolerance of this surface. Moreover, as $\mathrm{Ru}$ promotes water discharge at lower potentials than $\mathrm{Pt}$, the surface reaction between adsorbed $\mathrm{CO}$ and oxygenated species may take place with faster kinetics, explaining the enhanced electrocatalytic activity on $\mathrm{Pt} /$ Ru. At lower potentials $(E=0.4 \mathrm{~V}$, Fig. 20A), the initial specific molar current is of the same order of magnitude on both $\mathrm{Pt}$ and $\mathrm{Pt}_{80} \mathrm{Ru}_{20}$, and then it falls rapidly. In this case, water dissociation is not activated on $\mathrm{Pt}$, so that the surface reaction between adsorbed $\mathrm{CO}$ and $\mathrm{OH}$ cannot take place. On the contrary, the role of $\mathrm{Ru}$ is to diminish the potential of water discharge. The

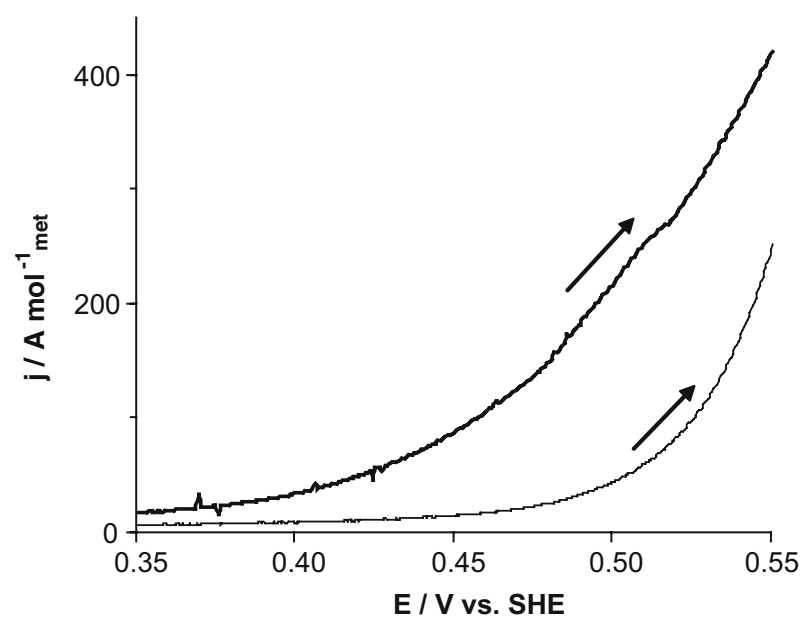

Fig. 19. Linear sweep voltammograms for $\mathrm{MeOH}$ electrooxidation on $\mathrm{Pt}$ (thin line) and $\mathrm{Pt}_{80} \mathrm{Ru}_{20}$ (thick line) nanoparticles deposited on

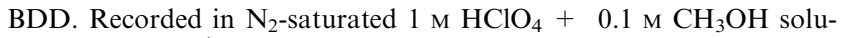
tion at $1 \mathrm{mV} \mathrm{s} \mathrm{s}^{-1}$ and $25^{\circ} \mathrm{C}$. 

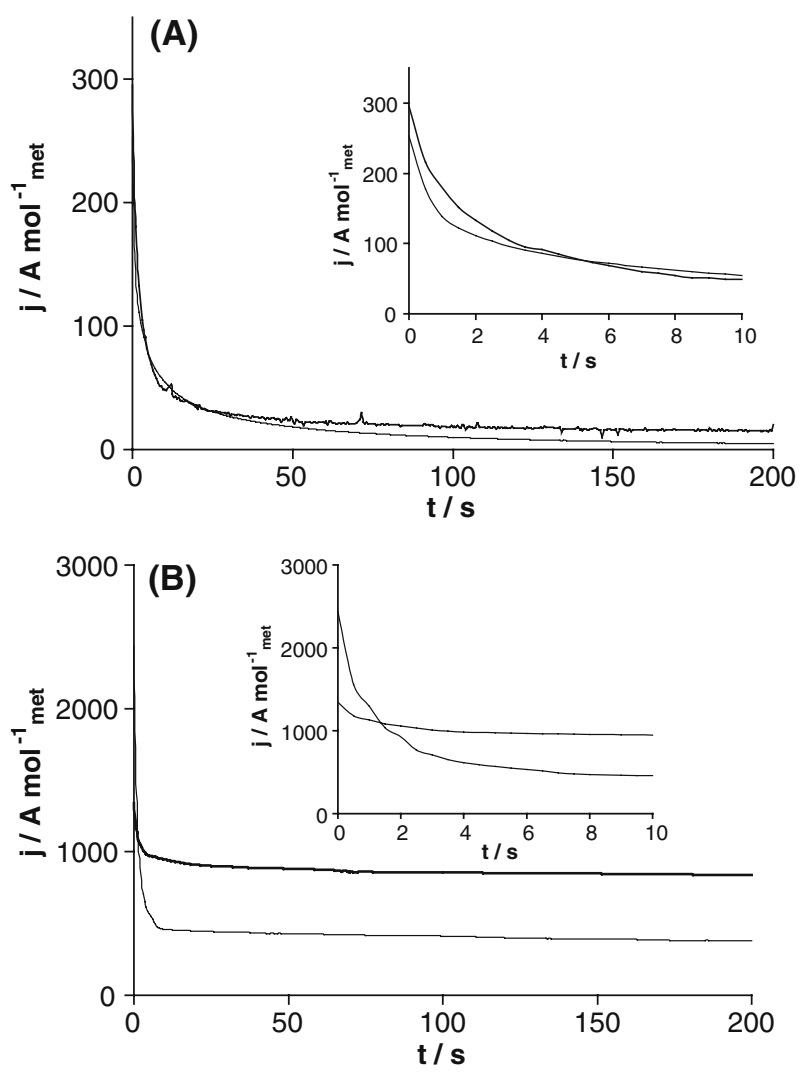

Fig. 20. Chronoamperometric curves for the electrooxidation of methanol on BDD-supported microemulsion-synthesized $\mathrm{Pt}$ (thin line) and $\mathrm{Pt}_{80} \mathrm{Ru}_{20}$ (thick line) nanoparticles at $0.4(\mathrm{~A})$ and $0.6 \mathrm{~V}(\mathrm{~B})$. Recorded in $1 \mathrm{M} \mathrm{HClO}_{4}+0.1 \mathrm{M} \mathrm{CH}_{3} \mathrm{OH}$ at $25^{\circ} \mathrm{C}$. Insets: zoom on the $0-10 \mathrm{~s}$ time domain.

surface reaction can thus take place earlier and with faster kinetics and the initial specific molar current is higher on $\mathrm{Pt} / \mathrm{Ru}$ than on $\mathrm{Pt}$. In this case also, the current decrease is less pronounced on the bimetallic surface and a higher specific molar current is maintained at $\mathrm{Pt}_{80} \mathrm{Ru}_{20}$ nanoparticles.

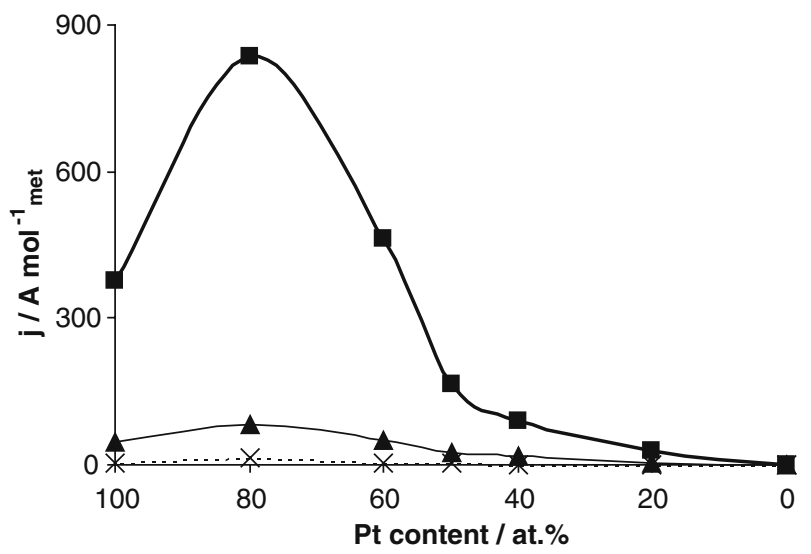

Fig. 21. Specific molar current after methanol electrooxidation during $200 \mathrm{~s}$ at constant potential. Recorded in $\mathrm{N}_{2}$-saturated $1 \mathrm{M} \mathrm{HClO}_{4}$ solution at $25^{\circ} \mathrm{C}$ and potentials of 0.4 (dashed line with cross symbols), 0.5 (thin solid line with triangles) and $0.6 \mathrm{~V}$ (thick solid line with squares).
Figure 21 summarizes the specific molar current of methanol oxidation at selected constant potentials $(0.4$, 0.5 and $0.6 \mathrm{~V}$ ), recorded after $200 \mathrm{~s}$ of electrolysis when all curves reached a plateau. Whatever the applied potential is, the evolution of the "steady state" specific molar oxidation current with the Pt content has similar profile. Among the synthesized compositions, the $\mathrm{Pt}_{80} \mathrm{Ru}_{20}$ nanoparticles are the most active. The activity decreases with the Pt content in the particles. This is in good agreement with the literature [55], and it is due to the stronger methanol adsorption on Pt-rich nanoparticles. It can be considered that the observed activity of the particles results from the balance between ability of alcohol adsorption on one hand, and $\mathrm{CO}$ tolerance on the other hand. According to the largely accepted mechanism of methanol electrooxidation on $\mathrm{Pt}$ [56], three $\mathrm{Pt}$ sites are required to adsorb one methanol molecule. Obviously, the probability to find three neighbouring Pt sites will decrease when the Pt content is decreased. Even if $\mathrm{Ru}$ plays an important role in the activity of $\mathrm{Pt} / \mathrm{Ru}$ surfaces, providing oxygenated species from water dissociation at lower potential compared to $\mathrm{Pt}$, it can also hinder the alcohol adsorption.

In order to obtain additional evidence on how the applied potential and the nature of the catalytic surface influence the oxidation, electrochemical impedance spectroscopy (EIS) has been performed. Potential modulations of $10 \mathrm{mV}$ in the frequency range between $100 \mathrm{kHz}$ and $0.01 \mathrm{~Hz}$ were used. Figure 22 shows Nyquist plots for methanol oxidation on $\mathrm{Pt}$ and $\mathrm{Pt}_{80} \mathrm{Ru}_{20}$ nanoparticles at constant potentials of 0.4 (A) and $0.6 \mathrm{~V}$ (B). The Nyquist plot recorded on Pt at $0.4 \mathrm{~V}$ (Fig. 22A) has a well-defined open semi-spherical shape, whereas those recorded on $\mathrm{Pt}_{80} \mathrm{Ru}_{20}$ (inset of Fig. 22A) exhibit the beginning of a terminal induction loop. This induction loop is also present on both Nyquist plots recorded at $0.6 \mathrm{~V}$ (see Fig. 22B). Such features of Nyquist plots for the electrooxidation of methanol on $\mathrm{Pt}$ [57] and $\mathrm{Pt} / \mathrm{Ru}$ [58] surfaces have already been observed. The large impedance arc for methanol oxidation at $0.4 \mathrm{~V}$ is indicative of a slow reaction rate. It can be assumed that surface poisoning by reaction intermediates (mainly $\mathrm{CO}_{\mathrm{ads}}$ ), which are strongly adsorbed on $\mathrm{Pt}$ active sites and hence block continuous methanol dehydrogenation, causes the observed slow kinetics. At the same potential, the diameter of the impedance arc at high frequencies is much smaller and the inductive loop appears at low frequencies on $\mathrm{Pt}_{80} \mathrm{Ru}_{20}$. The diameter of the impedance arcs decreases significantly, when the potential is increased up to $0.6 \mathrm{~V}$, indicating that charge-transfer resistance for methanol oxidation becomes smaller. Moreover, inductive loops are present on the two signals (see Fig. 22B), and the low frequency intersect of impedance with the real axis (polarization resistance: $R_{\omega} \rightarrow 0$ ) also decreases when the potential increases. This indicates that the overall methanol oxidation rate is faster [59]. The "pseudoinductive" behaviour means that the current signal follows a voltage perturbation with a phase delay [60], 

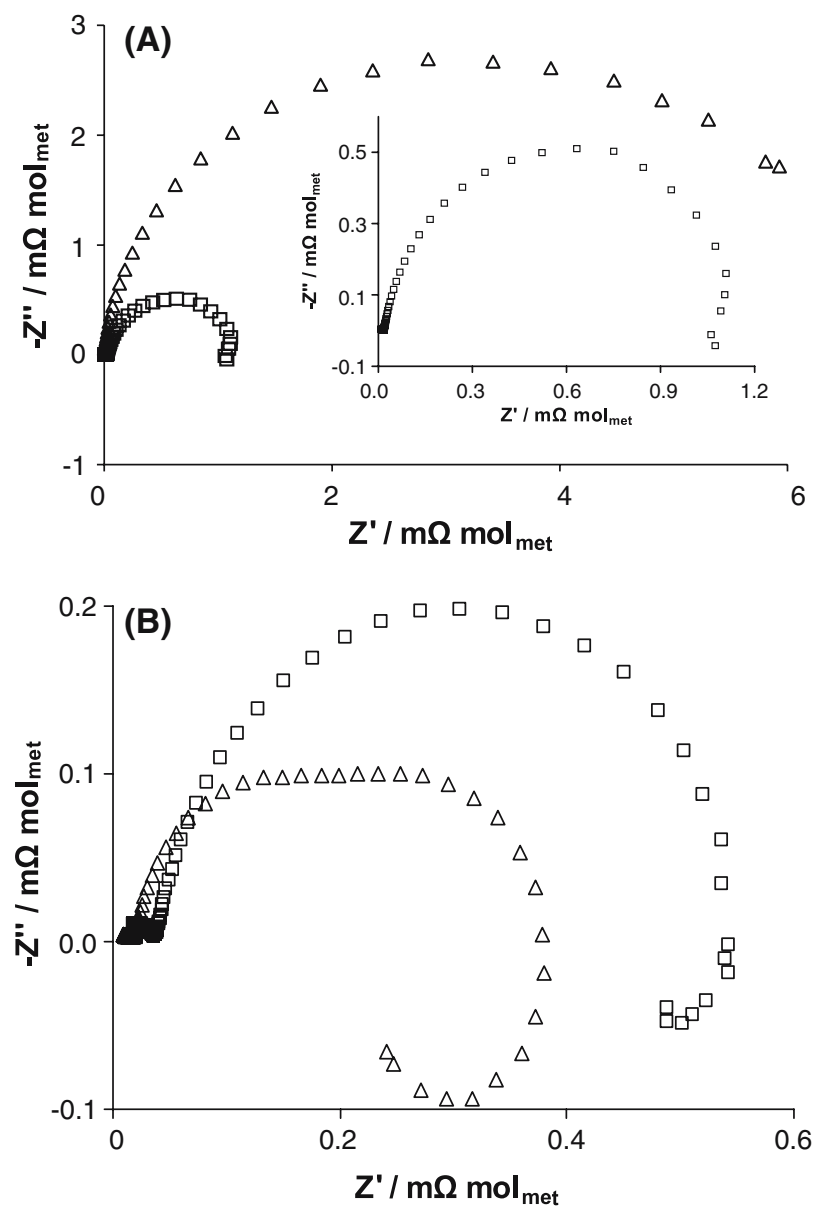

Fig. 22. Nyquist plots for methanol electrooxidation on Pt (squares) and $\mathrm{Pt}_{80} \mathrm{Ru}_{20}$ (triangles) nanoparticles deposited on BDD. Recorded in $\mathrm{N}_{2}$-saturated $1 \mathrm{M} \mathrm{HClO}_{4}+0.1 \mathrm{M} \mathrm{CH}_{3} \mathrm{OH}$ solution at $25^{\circ} \mathrm{C}$ at potentials of 0.4 (A) and $0.6 \mathrm{~V}(\mathrm{~B})$, with potential modulations of $10 \mathrm{mV}$ in the $100 \mathrm{kHz}$ to $0.01 \mathrm{~Hz}$ frequency range.

and it is generally associated with consecutive heterogeneous reactions involving adsorbed intermediates [61, 62]. This pseudo-inductive behaviour was observed firstly during corrosion tests; it was caused by pitting in the protection layer and subsequent corrosion of the metal through the holes of the protection layer. The occurrence of pseudo-inductive behaviour in the case of methanol electrooxidation can be explained similarly to corrosion. Initially, the reaction sites are covered with an adsorbed $\mathrm{CO}$ layer generated from methanol dehydrogenation (in analogy with the protective layer in corrosion). When the potential increases, some of the weakly adsorbed $\mathrm{CO}$ are oxidized, producing holes in the adsorbed $\mathrm{CO}$ layer (similarly to the beginning of pitting). Therefore, the subsequent methanol oxidation can take place through these holes, just like the corrosion of metal in the holes of the protective layer. Consequently, the changes in shape of the Nyquist plots can be ascribed to the beginning of water activation, which results in surface reaction between adsorbed $\mathrm{CO}$ and $\mathrm{OH}$ to yield free $\mathrm{Pt}$ sites. Occurrence of the pseudoinductive behaviour on $\mathrm{Pt}_{80} \mathrm{Ru}_{20}$ at lower potentials than on Pt indicates that water activation takes place earlier on the alloyed nanoparticles. This can explain also the smaller charge-transfer resistance against methanol oxidation observed at $0.4 \mathrm{~V}$ on $\mathrm{Pt}_{80} \mathrm{Ru}_{20}$ nanoparticles. Moreover, it must be pointed out that an electronic effect could reasonably be expected, due to the alloyed nature of $\mathrm{Pt} / \mathrm{Ru}$ nanoparticles. Weakening of the $\mathrm{Pt}-\mathrm{CO}$ bond can also be partially at the origin of the faster kinetics for the surface reaction between $\mathrm{CO}_{\mathrm{ads}}$ and $\mathrm{OH}$. However, when the potential is increased $(0.6 \mathrm{~V})$, the charge-transfer resistance against methanol oxidation on Pt becomes smaller. This indicates that, as soon as water is activated on a given surface, its electrocatalytic behaviour is dominated by its alcohol adsorption properties. In contrast, the weaker adsorption on $\mathrm{Pt}_{80} \mathrm{Ru}_{20}$ is counter-balanced, before water activation on Pt, by both the electronic effect and the bifunctional mechanism. These phenomena are not important enough to ensure superior activity of the alloyed surface when the surface reaction between adsorbed $\mathrm{CO}$ and $\mathrm{OH}$ can take place with appreciable kinetics on Pt. It has been aslo pointed out that the changes in shape of the Nyquist plots with the applied potential could be ascribed to involvement of adsorbed oxygenated species [63]. This is in good agreement with observations from $\mathrm{CV}$ and linear sweep voltammetry (see Figs. 18, 19, respectively).

\section{Conclusions}

Boron-doped diamond (BDD) electrode has been used as substrate for the study of deposited catalytic particles and nanoparticles. It was expected that the use of BDD could avoid the problems encountered with other common substrates, i.e. surface corrosion, oxide formation or electronic interactions with the deposit. It was supposed that BDD, due to the inert nature of its surface, could be a good substrate to investigate the electrocatalytic behaviour of particles without any major interference. Moreover, the mechanical and chemical stability of diamond electrodes also allows the use of "severe" methods for preparation of nanoparticles, such as thermal decomposition, without significant modifications of the surface properties of the substrate.

In our laboratory, we have deposited various types of metal and metal oxide nanoparticles on BDD substrates. The present article is focused on the electrochemical and electrocatalytic characterization of thermally decomposed $\mathrm{IrO}_{2}$ and $\mathrm{Au}$ nanoparticles, electrodeposited $\mathrm{Pt}$ particles, Pt DENs and microemulsion-synthesized $\mathrm{Pt} /$ $\mathrm{Ru}$ alloys nanoparticles deposited on BDD. The electrochemical response of such composite electrodes can be attributed solely to the the supported particles. With the exception of Pt DENs, all synthesized particles were electrocatalytically active, demonstrating the suitability of BDD as substrate for the electrochemical investigation of catalytic particles. Unsatisfactory preliminary results obtained on Pt DENs are presumably due to the insufficient removal of the capping polymer matrix, and 
appropriate conditions for dendrimer removal on BDD need to be developed. It is concluded that the BDD electrode is a suitable substrate for the investigation of supported catalytic nanoparticles. Its use avoids problems encountered with other common substrate electrodes such as surface oxide formation and corrosion.

\section{Acknowledgements}

The authors thank the CSEM (Centre Suisse d'Electronique et de Microtechnique SA, Neuchâtel, Switzerland) for preparing the BDD electrodes. Financial support from the Fonds National Suisse de la Recherche Scientifique is gratefully acknowledged.

\section{References}

1. K.-H. Meiwes-Broer, Metal clusters at surfaces-structure, quantum properties, physical chemistry (Springer-Verlag, Berlin, 2000).

2. O.V. Cherstiouk, P.A. Simonov and E.R. Savinova, Electrochim Acta 48 (2003) 3851.

3. T. Frelink, W. Visscher and J.A.R. van Veen, J. Electroanal. Chem. 382 (1995) 65.

4. M. Watanabe, H. Sei and P. Stonehart, J. Electroanal. Chem. 261 (1989) 375

5. H.B. Martin, A. Argoitia, U. Landau, A.B. Anderson and J.C. Angus, J. Electrochem. Soc. 143 (1996) L133.

6. Y.V. Pleskov, Russ. Chem. Rev. 68 (1999) 381.

7. S. Ferro, J Mater Chem 12 (2002) 2843.

8. G. Fóti, D. Gandini, C. Comninellis, A. Perret and W. Haenni, Electrochem. Solid-State Lett. 2 (1999) 228.

9. D. Gandini, E. Mahé, P.-A. Michaud, W. Haenni, A. Perret and C. Comninellis, J. Appl. Electrochem. 30 (2000) 1345.

10. J. Iniesta, P.-A. Michaud, M. Panizza, G. Cerisola, A. Aldaz and C. Comninellis, Electrochim. Acta 46 (2001) 3573.

11. M. Panizza, P.-A. Michaud, G. Cerisola and C. Comninellis, J. Electroanal. Chem. 507 (2001) 206.

12. M.A. Rodrigo, P.-A. Michaud, I. Duo, M. Panizza, G. Cerisola and C. Comninellis, J. Electrochem. Soc. 148 (2001) D60.

13. A.J. Saterlay, S.J. Wilkins, K.B. Holt, J.S. Foord, R.G. Compton and F. Marken, J. Electrochem. Soc. 148 (2001) E66.

14. F. Marken, A.S. Bhambra, D.-H. Kim, RJ Mortimer and S.J. Stott, Electrochem. Commun. 6 (2004) 1153.

15. K.J. McKenzie and F. Marken, Electrochem. Solid-State Lett. 5 (2002) E47.

16. K.J. McKenzie, D. Asogan and F. Marken, Electrochem. Commun. 4 (2002) 820.

17. I. Duo, C. Comninellis, S. Ferro and A. De Battisti. in A. Wieckowski, E.R. Savinova and C.G. Vayenas (Eds), Catalysis and electrocatalysis at nanoparticle surfaces, (Marcel Dekker, Inc. New York, 2003), pp. 877.

18. B. El Roustom, G. Fóti and C. Comninellis, Electrochem. Commun. 7 (2005) 398.

19. Y. Zhang, S. Asahina, S. Yoshihara and T. Shirakashi, Electrochim. Acta 48 (2003) 741.

20. Y. Zhang, V. Suryanarayanan, I. Nakazawa, S. Yoshihara and T. Shirakashi, Electrochim. Acta 49 (2004) 5235

21. F. Montilla, E. Morallon, I. Duo, C. Comninellis and J.L. Vazquez, Electrochim. Acta 48 (2003) 3891.

22. G. Siné and C. Comninellis, Electrochim. Acta 50 (2005) 2249.

23. K. Tsujimoto, S. Mitani, T. Teraji and T. Ito, Appl. Surf. Sci. 237 (2004) 488 .

24. O. Enea, B. Riedo and G. Dietler, Nano. Lett. 2 (2002) 241.

25. B. Marselli, J. Garcia-Gomez, P.-A. Michaud, M.A. Rodrigo and C. Comninellis, J. Electrochem. Soc. 150 (2003) D79.
26. J. Wang and G.M. Swain, J. Electrochem. Soc. 150 (2003) E24.

27. J. Wang, G.M. Swain, T. Tachinaba and K. Kobashi, Electrochem. Solid-State Lett. 3 (2000) 286.

28. J.-S. Gao, T. Arunagiri, J.-J. Chen, P. Goodwill, O. Chyan, J. Perez and D. Golden, Chem. Mater. 12 (2000) 3495.

29. T. Kobayashi, M. Haruta, H. Sano and M. Nakane, Sens. Actuators 13 (1988) 339.

30. T. Kobayashi., M. Haruta, S. Tsubota, H. Sano and B. Delmon, Sensors Actuators B 1 (1990) 222.

31. A. Hamnett. in W. Vielstich, H.A. Gasteiger and A. Lamm (Eds), Handbook of fuel cells - fundamentals, technology and applications, (John Wiley \& Sons, Ltd, New York, 2003), pp. 305.

32. C. Lamy and E.M. Belgsir. in W. Vielstich, H.A. Gasteiger and A. Lamm (Eds), Handbook of fuel cells-fundamentals, technology and applications, (John Wiley \& Sons, Ltd., New York, 2003), pp. 323.

33. T.R. Ralph and M.P. Hogarth, Platinum Metals Rev. 46 (2002) 117.

34. M. Boutonnet, J. Kizling and P. Stenius, Colloids Surf. 5 (1982) 209.

35. J. Solla-Gullón, V. Montiel, A. Aldaz and J. Clavilier, J. Electroanal. Chem. 491 (2000) 69.

36. R.M. Crooks, M. Zhao, L. Sun, V. Chechik and L.K. Yeung, Acc. Chem. Res. 34 (2001) 181.

37. Y.-G. Kim, S.-K. Oh and R.M. Crooks, Chem. Mater. 16(2004) 167.

38. H. Ye, R.W.J. Scott and R.M. Crooks, Langmuir 20 (2004) 2915.

39. S.H. Glarum and J.H. Marshall, J. Electrochem. Soc. 127 (1980) 1467.

40. L.A. da Silva, V.A. Alves, M.A.P. da Silva, S. Trasatti and J.F.C. Boodts, Electrochim. Acta 42 (1997) 271.

41. S. Trasatti, Electrochim. Acta 36 (1991) 225.

42. A. De Battisti, G. Lodi, L. Nanni, G. Battaglin and A. Benetti, Can. J. Chem. 75 (1997) 1759.

43. L.D. Burke and D.P. Whelan, J. Electroanal. Chem. 124 (1981) 333.

44. L.D. Burke and D.P. Whelan, J. Electroanal. Chem. 162 (1984) 121.

45. S. Ardizzone, A. Carugati and S. Trasatti, J. Electroanal. Chem. 126 (1991) 287.

46. J. Rolewicz, C. Comninellis, E. Plattner and J. Hinden, Electrochim. Acta 33 (1988) 573.

47. M. Paunovic and M. Schlesinger, Fundamentals of electrochemical deposition (John Wiley \& Sons, Inc., New York, 1998).

48. B. Scharifker and G. Hills, Electrochim. Acta 28 (1983) 879.

49. F. Gloaguen, J.M. Léger, C. Lamy, A. Marmann, U. Stimming and R. Vogel, Electrochim. Acta 44 (1999) 1805.

50. J. Clavilier and D. Armand, J. Electroanal. Chem. 199 (1986) 187.

51. Y. Takasu, Y. Fujii, K. Yasuda, Y. Iwanaga and Y. Matsuda, Electrochim. Acta 34 (1989) 453.

52. K.-W. Park, J.-H. Choi, B.-K. Kwon, S.-A. Lee, Y.-E. Sung, H.Y. Ha, S.-A. Hong, H. Kim and A. Wieckowski, J. Phys. Chem. B 106 (2002) 1869

53. A.S. Aricò, P.L. Antonucci, E. Modica, V. Baglio, H. Kim and V. Antonucci, Electrochim. Acta 47 (2002) 3723.

54. A. Hamnett. in A. Wieckowski (Ed), Interfacial electrochemistry-theory, experiments, and applications, (Marcel Dekker, Inc, New York, 1999), pp. 843.

55. J. Solla-Gullón, F.J. Vidal-Iglesias, V. Montiel and A. Aldaz, Electrochim. Acta 49 (2004) 5079.

56. M.P. Hogarth and T.R. Ralph, Platinum Metals Rev. 46 (2002) 146.

57. R.E. Melnick and G.T.R. Palmore, J. Phys. Chem. B 105 (2001) 1012 .

58. G. Wu, L. Li and B.-Q. Xu, Electrochim. Acta 50 (2004) 1.

59. I.M. Hsing, X. Wang and Y.-J. Leng, J. Electrochem. Soc. 149 (2002) A615.

60. Y.-J. Leng, X. Wang and I.M. Hsing, J. Electroanal. Chem. 528 (2002) 145.

61. R.D. Armstrong and M. Henderson, J. Electroanal. Chem. 39 (1972) 81 .

62. D.A. Harrington and B.E. Conway, Electrochim. Acta 32 (1987) 1703.

63. R.E. Melnick and G.T.R. Palmore, J. Phys. Chem. B 105 (2001) 9449. 